\title{
PRODUÇÃO DE MATÉRIA SECA, NODULAÇÃO E ABSORÇÃO DE NUTRIENTES PELA SOJA [Qflycine max (L.) Merrill], EM FUNÇÃO DE NIVEIS DE FÓSFORO E ZINCO, EM SOLOS DE MINAS GERAIS
}

FRANCISCO MOREL FREIRE

Engenheiro-Agrônomo

Orientador: Dr. José Renato Sarruge

\footnotetext{
Disserłação apresentada à Escola Superior de Agricultura "Luiz de Queiroz", da Universidade de São Paulo, para obłenção do grau de Mestre em Solos e Nutrição de Plantas.
}

PIRACICA B A

Estado de São Paulo - Brasil

Maio, 1978 
ii.

Aos meus pais, DEDICO. 


\section{AGRADECIMENTOS}

A Escola Superior de Agricultura "Luiz de Queiroz" e

à Empresa de Pesquisa Agropecuária de Minas Gerais, pela oportunida de oferecida.

Ao Conselho Nacional de Desenvolvimento Científico e Tecnológico - CNPq, pela bolsa de estudos concedida.

Ao Prof. Dr. José Renato Sarruge, pela atenciosa ori entação.

Ao Prof. Gilberto Diniz de Oliveira, pela orientação na realização das análises químicas.

Ao Prof. Dr. José Mário Braga, pelas sugestões.

Ao Prof. Dr. Roberto Ferreira de Novais, pela versão do resumo para o inglês.

Ao Prof. Paulo César Lima, pelas análises estatísticas。

Ao Prof. Valdemar António Demétrio, pela revisão do texto.

A Eng:-Agr. Lucy Maria da Silva e aos laboratoristas Lurdes Aparecida Dário, Marcos Antōnio Maistro e Francisco Carlos Am toniolli, pela colaboração na realização das análises químicas. Ao Sr. Luiz Carlos Veríssimo, pela orientação na localização das publicações.

Ao Sr. Ângelo Smaniotto, pela ajuda na condução do ex perimento. 
A Srta. Maria Izalina Ferreira Alves e ao Sr. Octävio Frassetto, pelos trabalhos de datilografia e impressão, respec tivamente.

$$
\text { A todos que, direta ou indiretamente, contribuiram }
$$
para a realização deste trabalho. 
Pág.

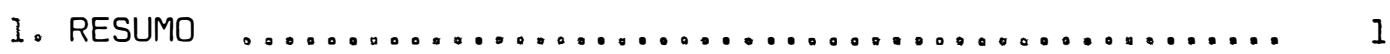

2. INTRODUÇÃO $\ldots \ldots \ldots \ldots \ldots \ldots \ldots \ldots \ldots \ldots \ldots \ldots \ldots \ldots \ldots \ldots \ldots \ldots \ldots \ldots$

3. REVISÃO DE LITERATURA $\ldots \ldots \ldots \ldots \ldots \ldots \ldots \ldots \ldots \ldots \ldots \ldots \ldots \ldots \ldots \ldots \ldots$

3.1 - Fertilização Fosfatada $\ldots \ldots \ldots \ldots \ldots \ldots \ldots \ldots \ldots \ldots$

3.2 - Fertilização com Zinco $\ldots \ldots \ldots \ldots \ldots \ldots \ldots \ldots \ldots . \ldots . \ldots . . \ldots$

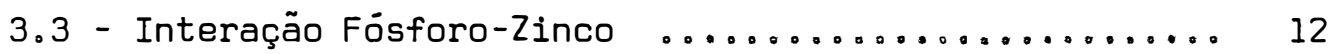

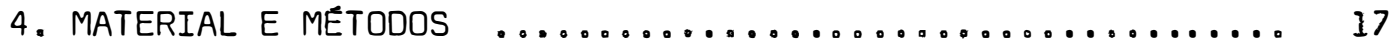

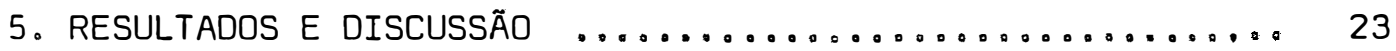

5.1 - Produção de Matéría Seca: Raízes, Parte Aérea e Nó-

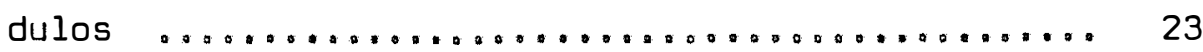

5.2 - Concentração de Nutrientes em Função dos Níveis de Fósforo, Zinco e Solos „.................. 27

5.2 .1 - Concentração de nitrogênio $\ldots \ldots \ldots \ldots \ldots \ldots 27$

5.2 .2 - Concentração de fósforo $\ldots \ldots \ldots \ldots \ldots \ldots . \ldots 32$

5.2 .3 - Concentração de potássio ........... 36

5.2 .4 - Concentração de cálcio ............. 42

5.2 .5 - Concentração de magnésio ........... 46

5.2 .6 - Concentração de zinco ............. 49

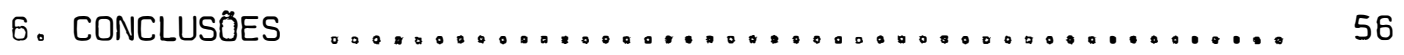

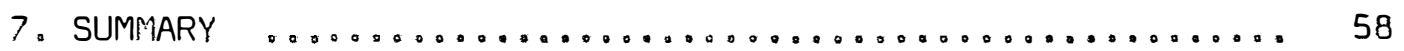

9. LITERATURA CITADA $\ldots \ldots \ldots \ldots \ldots \ldots \ldots \ldots \ldots \ldots \ldots \ldots \ldots \ldots \ldots \ldots \ldots \ldots$ 


\section{RESUMO}

Com o objetivo de estudar o efeito de níveis de fósforo e zinco na produção de matéría seca, nodulação e absorção de nu trientes pela cultura da soja (Glycine $\max \left(L_{.}\right)$Merril cv. 'UFV-l'), foi desenvolvido um experimento em casa de vegetação, na Escola Superior de Agricultura "Luiz de Queiroz", utilizando-se solos do Estado de Minas Gerais. Foram testados três nívels de fósforo 10,200 e $400 \mathrm{~kg}$ de $\left.\mathrm{P}_{2} \mathrm{O}_{5} / \mathrm{ha}\right)$ e três de zinco $(0,15$ e $30 \mathrm{~kg}$ de sulfato de zinco/ha), em três solos. Os solos usados foram os seguintes: Latos solo Vermelho Amarelo (LV), Latossolo Vermelho Escuro textura média (LEm) e Latossolo Vermelho Escuro (LE). Fol utilizado um delineamen to experimental inteiramente casualizado num esquema fatorial $3^{2} \times 3$, com duas repetiçöes. Cada parcela fol constituída de um vaso conten do $7 \mathrm{~kg}$ de terra e 2 plantas. As sementes no plantio foram inocula- 
2.

das com estirpes de Rhizobium japonicum.

Nestas condições, a adubação fosfatada se fez necessáría para uma boa produção de matéría seca e nodulação. A fertilização com zinco não aumentou a produção de matéria seca das plantas. As menores produções foram verificadas no LEm, no entanto, este so10, juntamente com o LV, foram os substratos que propiciaram as maio res nodulações. As concentrações de $P$ e $Z n$ nas plantas aumentaram pe las adubações com fósforo e zinco, respectivamente. Por outro lado, as concentraçōes de N, Ca, Mg e Zn decresceram pela adubação fosfatada, sendo sugerido um efeito de diluição, propiciado pelo intenso crescimento das plantas. A fertilização fosfatada, na maior dose, di minuiu os teores de $K$ nas folhas velhas $e$ aumentou nas novas $e$ hastes. mostrando ter havido translocação do referido nutriente. 


\section{INTROOUÇĀO}

O Brasil tem experimentado aumentos suproendentes de produção de soja nos ültimas anos. De um total de 5.011 .614 t em 1973, passou a 11.226.545 t em 1976, sendo atualmente o $2^{\circ}$ produtor mundial. De modo semelhante, a produção de soja em Minas Gerais vem crescendo sensivelmente, passando de 36.318 t em 1973 para 105.515 $t$ em 1976 (BRASIL, 1974; BRASIL, 1976).

Este incremento intenso de produção,em Minas Gerais, deveu-se, além da utilização de uma tecnologia mais avançada, à exploração de novas äreas como as dos cerrados. Embora com algumas con dições favoráveis, como as topogräficas, os solos dos mesmos são conhecidamente pobres em nutrientes.

Nos principais grupos de solos das regiões do Triāngulo Mineiro e Alto Paranalba, três dos quais foram objetos de estu 
do no presente trabalho, o fósforo apresenta-se como principal nutriente limitante da produção de soja (PIPAEMG, 1973). Por outro la do, existe uma falta de informações para o Estado de Minas Gerais em relação ao emprego de micronutrientes na cultura da soja. O seu emprego é sugerido somente nas condições em que seja comprovada sua deficiência (PIPAEMG, 1973).

Em face do exposto, o presente trabalho foi desenvol vido com o objetivo de estudar o efeito de níveis de fösforo e zin co na produção de matéria seca, nodulação e absorção de nutrientes pela cultura da soja, em três solos do Estado de Minas Gerais. 
5.

\section{REVISÃO DE LITERATURA}

\section{1 - Fertilização Fosfatada}

A utilização pelas plantas do fósforo nativo do solo e do adicionado ao mesmo, como fertilizante, pôde ser estudado por WELCH et alii (1949) graças à técnica do elemento marcado. Verifica ram que a porcentagem de fósforo na planta, proveniente do fertilizante, era inversamente proporcional ao nível de fósforo no solo e diretamente proporcional às quantidades aplicadas na adubação. Observaram, também, que a absorção de fósforo pelas plantas, nos seus primeiros estágios de crescimento, foi muito maior quando o fertili zante foi colocado na linha de plantio, do que quando foi distribuí do em toda área e incorporado ao solo.

BUREAU et alii (1953), estudando o efeito de fontes de fósforo utilizadas na fertilização do solo,sobre a produção de grãos 
matéria seca e absorção de fósforo pelas plantas, verificaram também que a porcentagem do fósforo total na planta, derivado do ferti lizante, era inversamente proporcional ao seu nível no solo.

0 efeito do nível de fósforo na solução nutritiva so bre várias características agronômicas e químicas da soja, foram es tudadas por HOWELL (1954). Verificou que, o aumento do nivel de fós foro de 2 para 10 ppm, na solução nutritiva, proporcionou um aumento na altura e peso das plantas, uma maior produção de grãos e mais alto conteúdo de óleo nos mesmos, em todas as variedades usadas. Ob servou também que, quando foram empregadas doses elevadas, as varie dades comportaram-se diferentemente, existindo aquelas que responde ram favoravelmente até altos níveis de fósforo, como 112 ppm, enquanto que outras já eram prejudicadas ao nível de 50 ppm.

WEBER e CALOWELL (1962) verificaram que aplicaçōes pe sadas de fósforo, com ou sem potássio, resultaram em clorose das plantas de soja. Evidenciou-se que o potássio era limitante nas plan tas que receberam altas doses de fósforo e que o manganès era o nutriente limitante nas plantas que receberam altas doses de fósforoe potássio, demonstrando, assim, que grandes quantidades de fósforo podem prejudicar a cultura, em certos casos, provocando a deficiência de outros elementos.

FLETCHER e KURTZ (1964) cultivaram duas variedades de soja em casa de vegetação, com quantidade de fósforo variando de 0 (zero) a $4.950 \mathrm{~kg} / \mathrm{ha}$. As altas doses de fósforo afetaram diferente- 
mente as variedades. Enquanto uma jä apresentava, na dose de $2.948 \mathrm{~kg}$ de $P / h a$, sintomas de toxidez e pouco desenvolvimento, na outra o desenvolvimento reduzido ocorreu somente a mais altos níveis de fósfo ro, não apresentando outros sintomas de toxidez. As porcentagens de $P$ e $K$ nas folhas aumentaram com o aumento das doses de fósforo.

PEREIRA (1972), estudando o efeito de fontes e doses de fósforo na adubação da soja, encontrou, além de um aumento da con centração do referido nutriente, uma elevação dos teores de $N, K$ e Ca e diminuição dos de Mg na folha, com aumento das doses de cada fosfato.

E bastante conhecido o efeito positivo do fósforo sobre o rendimento da soja, bem como sua influência sobre outras características,como altura da planta, altura da inserção da 1 . vagem. nodulação, etc.

KAMPRATH e MILLER (1958) desenvolveram trabalhos de campo visando à determinação da relação entre a produção de soja e o nível de fósforo no solo. Para tanto, os solos foram agrupados em diversas classes quanto ao nível de $P$, ou seja, baixo, 4 a 10 ppm, médio, 11 a 31 ppm, alto, 32 a 56 ppm, e muito alto, maior que 56 ppm. Observaram haver uma relação positiva entre a produção de soja e o nível de fósforo no solọ. Estudos em casa de vegetação, realiza dos também por estes pesquisadores, mostraram resultados semelhantes aos obtidos em condições de acampo.

MIYASAKA et alii (1960), MIYASAKA et alii (1962), MI 
YASAKA et alii (1964a), MIYASAKA et alii (1966), MASCARENHAS E MIYA SAKA (1968) e MASCARENHAS et alii (1970) obtiveram respostas significativas na produção de soja em solos do Estado de São Paulo, quan do o fósforo foi adicionado na adubação.

A influência da adição de sais de fósforo, potássio e cálcio, sobre a nodulação da soja, foi estudada por MOOY e PESEK (1966). Observaram que a nodulação dada em peso dos nódulos, espera da no fim do florescimento, foi triplicada com a aplicação de 450 a $562 \mathrm{~kg}$ de $\mathrm{P} / \mathrm{ha}$ e 675 a $900 \mathrm{~kg}$ de $\mathrm{K} / \mathrm{ha}$, demonstrando assim, que uma alta nodulação requer elevadas doses de $P$ e $K$.

GOEPFERT (1971) e GOEPFERT e FREIRE (1972), trabalhan do com solos do Rio Grande do Sul, além de observarem o efeito esti mulante do fósforo na produção de matéría seca a rendimento da soja, verificaram sua importância para uma boa nodulação.

PEREIRA (1972), estudando o efeito de fontes e doses de fósforo em um Latossolo Vermelho Escuro distrófico, textura média, sob vegetação campo cerrado, no Estado de Goiás, para a cultura da soja Mineira, observou aumento no peso dos nódulos secos, das vagens e produção de grãos com as doses de todas as fontes.

No Estado de Minas Gerais, BRAGA et alii (1972), con duzindo experimentos em quatro locais do Triângulo Mineiro, num mes mo Latossolo Vermelho Escuro textura média, e doses de 0, 100, 200 e $300 \mathrm{~kg}$ de $\mathrm{P}_{2} \mathrm{O}_{5} / \mathrm{ha}$, encontraram uma relação linear entre a produção de soja e níveis de fósforo aplicado. LIMA et alii (1974), além de encontrarem respostas para a produção, verificaram que a adubação 
fosfatada proporcionou aumento na altura das plantas e inserção da 1. vagem.

\section{2 - Fertilização com Zinco}

Segundo SALAKO et alii (1975), não se considerando a variabilidade existente entre as culturas e as suas capacidades em absorver o zinco do solo, as respostas das plantas à fertilização com este micronutriente, são frequentemente influenciadas pelas quan tidades aplicadas e tipo de solo. Trabalhos têm mostrado uma correlação positiva entre as doses de zinco aplicadas e a sua absorção pelas plantas.

VIETS et alii (1954), cultivando 26 culturas, com e sem aplicação de zinco, em duas áreas adjacentes, uma das quais havia produzido severos sintomas de deficiência de zinco em milho, ob servaram que, entre as culturas susceptíveis à deficiência deste elemento, se encontrava a soja. Observaram também que, pela adubação com zinco na base de $26 \mathrm{~kg}$ de $\mathrm{Zn} / \mathrm{ha}$, como $\mathrm{ZnSO}_{4}$, as severidades dos sintomas poderiam ser diminufdas ou prevenidas inteiramente. 0 conteúdo de zinco nas folhas maduras mais jovens, de todas as culturas amostradas, foi aumentado com a sua aplicação.

Um experimento de campo foi conduzido por LEE e CRAD DOCK (1969) para estudar a influência do pH do solo, adição de micronutrientes e outras práticas de manejo, sobre a produção de soja. 0 solo onde o experimento foi instalado apresentava 13 e 2 ppm de $2 n$ 
nos horizontes $A p(0-13 \mathrm{~cm})$ e $A_{2}(13-53 \mathrm{~cm})$, respectivamente. Obser varam que a adição de $\mathrm{ZnSO}_{4}$ ao solo aumentou as concentrações de $\mathrm{Zn}$, Fe e Mn nas folhas e diminuiu a altura das plantas e produção.

Foi conduzido trabalho de campo por MARTENS et alii (1974), para determinar níveis toleráveis de aplicações de $B$, Cu e Zn para a cultura da soja. Vários níveis desses micronutrientes foram aplicados aos solos anualmente, por 6 anos. Verificaram que o crescimento das plantas e a produção de sementes, após os anos de aplicação, não foram afetados por doses altas como $3,3 \mathrm{~kg}$ de $8,8,4$ $\mathrm{kg}$ de Cu e $11,1 \mathrm{~kg}$ de $\mathrm{Zn} / \mathrm{ha}$. Estas relativa tolerância da soja às al tas aplicações de B, Cu e Zn, foram atribuídas, em parte, a um decréscimo na absorção desses micronutrientes em pH próximo da neutra lidade. Observaram, também, que as concentrações de B e $Z n$ nas plan tas, geralmente aumentaram com os níveis de aplicação desses micronutrientes aos solos.

Pela necessidade de mais informações sobre a fertili zação da soja com zinco, experimentos foram desenvolvidos por SALAKO et alii (1975) em câmara de crescimento,casa de vegetação e campo, com os objetivos de estudar respostas morfológicas da soja à aplica çāo deste micronutriente,investigar os seus efeitos na produção,com parar várias fontes do mesmo e verificar seu efeito residual em cul tura posterior de soja. Em síntese, não foram observados efeitos das doses de zinco sobre a altura das plantas, peso de matéria seca e produção de grãos. Por outro lado, aumentos na absorção e concentração de Zn nas plantas, sugeriram evidências que esta cultura po- 
derá responder à adubação com este micronutriente.

Trabalhos mostrando o efeito positivo das aplicações de zinco na produção de soja, são encontrados na literatura. Apesar disto, o seu efeito positivo nem sempre tem sido comprovado.

FREITAS et alii (1960), trabalhando em um solo pertencente ao grande grupo do Latossolo Húmico sob vegetação de cerrado, do Estado de Goiás, verificaram respostas pelas culturas do milho e soja à aplicação de zinco.

Experimentos de adubação NPK, associada. ou näo aos micronutrientes $\mathrm{Cu}, \mathrm{Zn}$, Mo, Mn e B, com aplicação de calcário e com presença e ausēncia de Mg, em solos sob vegetação de cerrado, utili zando as culturas de soja, milho e algodão como testes, foram condu zidos por BRITTO et alii (197I). Em todos os trabalhos constatou-se que a adubação preponderante é a de macronutrientes associada a zin co, pois proporcionou produções mais elevadas.

Um experimento incluindo 5 níveis de zinco $(0,1,3$, 9 e $27 \mathrm{~kg}$ de $\mathrm{Zn} / \mathrm{ha}$ ) foi estabelecido pela EMBRAPA (1976), no ano agrícola 1972/73, em um Latossolo Vermelho Escuro argiloso, sob vege tação de cerrado, o qual havia sofrido calagem para elevar o pH a 7,0. Anualmente foi aplicada uma adubação de manutenção, sendo que o zinco só foi aplicado quando do início do experimento. Foram cultivados milho nos 2 primeiros anos e sorgo e soja posteriormente. Foi observada pelos dados de produção, para as várias culturas, uma resposta ao zinco, sendo que a dose de $9 \mathrm{~kg}$ de $\mathrm{Zn} /$ ha mostrou-se su- 
ficiente para manter boas produções por, pelo menos, quatro colheitas consecutivas.

Em experimentos conduzidos por MIYASAKA et alii (1962, 1964b e 1966), em Terra Roxa misturada com argilito glacial, em solo do arenito de Botucatu, e num solo pobre de Itararé, Estado de São Paulo, não foi observado efeito benéfico na produção de soja pe la aplicação de uma mistura de micronutrientes $(\mathrm{Zn}, \mathrm{Cu}, \mathrm{B}$ e Mo). MAS CARENHAS e MIYASAKA (1967), GOEPFERT (1971) e MASCARENHAS et alii (1973) também não obtiveram respostas na produção de soja pela apli cação de micronutrientes. Segundo MASCARENHAS et alii (1977), a fal ta de respostas pela soja à aplicação de micronutrientes se deve pro vavelmente ao fato dos calcários usados como corretivos, superfosfato simples e triplo,apresentarem teores suficientes desses micronutrientes para o bom desenvolvimento das plantas.

\section{3 - Interação Fösforo-Zinco}

Muitas referências podem ser encontradas na literatu ra evidenciando o efeito antagónico entre estes nutrientes.

BURLESON et alii (1961) observaram, em condições de campo, severa clorose e pouco desenvolvimento das plantas de milho nas parcelas que foram adubadas com fósforo. 0 mil ho não adubado com este elemento se apresentava com coloração normal. A suspeita de de ficiència de zinco foi confirmada quando a clorose foi corrigida pe la pulverização com $2 \mathrm{nSO}_{4}$. Em outro experimento, foi observado leve 
sintoma de deficiência de zinco nas plantas de tomate onde o fósforo foi aplicado sozinho. A concentração de $Z n$ no tecido foliar foi reduzida de 24,6 ppm na testemunha para 16,6 ppm nas plantas adubadas com este macronutriente. Em trabalho realizado em casa de vegetação, com feijão, também observaram sintomas de deficiència de ziñ co nas plantas adubadas com fósforo, não chegando a afetar o desenvolvimento das mesmas.

BOAWN e LEGGETT (1964) cultivaram batatas em condições de campo e solução nutritiva, a níveis de $\mathrm{Zn}$ e $\mathrm{P}$ que poderiam produzir plantas variando de nenhuma à severa deficiência de zinco. Foi observado que o aumento do suprimento de $P$ induziu uma desordem no crescimento, a qual poderia ser eliminada por um aumento no suprimento de $\mathrm{Zn}$. Verificaram, também, que o aparecimento de sintomas de deficiência e a correção dos mesmos não foram bem correlacionados com as mudanças nas concentrações de $\mathrm{Zn}$ no caule e folhas. Para estes autores, as altas concentraçöes de $\mathrm{P}$ nos tecidos, resultando em razões $\mathrm{P} / \mathrm{Zn}$ de altos valores, pareceu oferecer uma melhor explicação para os ocorridos. As plantas sadias apresentaram uma razão de concentração $\mathrm{P} / \mathrm{Zn}$ inferior a 400 , ao passo que, as deficientes em zinco, apresentaram razões superiores àquele valor.

Em experimentos em casa de vegetação, ELLIS JR. et alii (1964) verificaram um decréscimo nas concentraçöes de Zn em fei jão e milho pela aplicação de 492 e $737 \mathrm{~kg}$ de $\mathrm{P} / \mathrm{ha}$. Verificaram,tam bém, que as aplicações de Zn resultaram em decréscimo nas concentra 
ções de $P$ das folhas de feijão que recebeu alta dose de fósforo. Deficiència de zinco induzida por fósforo foi observada por BOAWN e BROWN (1968) em feijões e batatas. Em ambas as cul turas, o fósforo induziu a deficiência sem que a concentração ou a acumulação de zinco variasse apreciavelmente. Segundo estes pesquisadores, os resultados suportaram a hipótese de que o metabolismo normal depende de um balanço fisiológico entre o fósforo e o zinco. Duas variedades de soja, diferentes quanto à sensibi lidade a altos teores de fósforo, foram cultivadas em solução nutrí tiva contendo vários níveís de $P$ e $Z n$, por PAULSEN e ROTIMI (1968). Verificaram que, os altos níveis de fósforo, diminuíram o crescimen to da variedade sensivel, mais do que da variedade tolerante, mas o decréscimo nas concentrações de $\mathrm{Zn}$ ocorreram igualmente em ambas as variedades. A adição de $Z n$ superou o efeito do $P$ na tolerante, mas não na sensivel, indicando existir dois diferentes efeitos prejudiciais do fósforo. Foi observado, também, que a deficiência de zinco afetou o crescim nto de todas as partes da planta e que as concentrações de $P$ nas folhas decresceram quando as plantas deficientes neste elemento foram supridas com zinco.

LO e REISENAUER (1968), estudando a influência do fornecimento de $Z n$ sobre a produção e composição química da alfafa eultivada, observaram estar os sintomas de deficiência desse micronutriente associados a altos nIveis de fósforo nas folhas. A razão $P / Z n$, encontrada nas folhas de plantas normais, foi inferior a 800 . 
Estudos realizados em casa de vegetação por BROWN et alii (1970), usando milho como planta teste, mostraram que, além do fósforo acentuar os sintomas de deficiência de zinco nas plantas que não receberam este micronutriente, as aplicações de zinco tenderama acentuar também os sintomas de deficiència de fósforo nas plantas com nível zero deste macronutriente. Citam, também, que a deficiència, em ambos os casos, foi prontamente corrigida mediante aplicaçöes do elemento apropriado.

0 efeito antagōnico entre estes nutrientes, nem sempre tem sido comprovado. BOAWN et alii (1954), em vários experimentos para determinar se os altos níveis de fosfato no solo se consti tuem num fator para ocorrência de deficiència de $Z n$ em feijão, veri ficaram que altas aplicações de fósforo não afetaram a absorção do Zn nativo ou aplicado. Segundo estes autores, uma interpretação do efeito do fósforo na absorção do zinco tornou-se complicada pelapre sença de uma apreciável quantidade deste micronutriente nos tratamentos com fosfato.

Experimentos com cultivo em areia, com várias culturas, foram conduzidos por BINGHAM (1963). Não foram observadas defí ciências de $\mathrm{Zn}$ induzidas por $P$. No caso da cultura do citrus, os ní veis de zinco na planta aumentaram com a elevação do $P$ no substrato. Considerações sobre a natureza do discutido efeito säo também encontradas na literatura.

De acordo com LANGIN et alii (1962), o efeito prefu- 
16.

dicial do P na utilização do Zn é fisiológico, ocorrendo dentro da planta, sendo provável nas células das raízes, e não uma simples prẹ cipitação de fosfato de zinco fora das mesmas.

BAHIA (1973), através de estudos visando identificar as relaçōes entre a adubação fosfatada e a calagem, com o zinco, na nutrição do milho, verificou que a interação entre o fósforo e o re ferido micronutriente, na planta, ocorreu principalmente nas raizes, havendo redução na translocação do zinco para as folhas.

Uma série de experimentos com raízes destacadas de cevada e plantas inteiras, em solução nutritiva e solo, visando esclarecer o problema, foi realizado por MALAVOLTA e LOPEZ GOROSTIAGA (1974). Segundo estes autores, a deficiēncia de zinco induzida pelo fósforo pode ser explicada pela operação de vários processos: inibí ção não competitiva da absorção de zinco; precipitação do zinco pelo fosfato na superfície das raízes: redução na translocação para a parte aéreas efeito de diluição resultante das altas taxas de crescimento causadas pelo fosfato. 
17.

4. MATERIAL E METODOS

0 experimento foi conduzido em casa de vegetação, na Escola Superior de Agricultura "Luiz de Queiroz", no perfodo de Janeiro a março de 1977.

Foram testados três níveis de fósforo e três de zinco, em três solos. O delineamento experimental usado foi o inteiramente casualizado. num esquema fatorial $3^{2} \times 3$ com 2 repetições, per fazendo um total de 54 parcelas (PIMENTEL GOMES, 1976). Cada parcela foi constituida de um vaso com 2 (duas) plantas de soja (Glycine $\max \left(L_{0}\right)$ Merril), da cultivar 'UFV-I'。

Os níveis de fósforo e zinco são apresentados na Tabela 1.

0 sulfato de zinco empregado foi o heptahidratado $\left(\mathrm{ZnSO}_{4} \cdot 7 \mathrm{H}_{2} \mathrm{O}\right)$ 
Tabela 1 - Níveis e Fontes dos Nutrientes Utilizados.

\begin{tabular}{ccc}
\hline Niveis & $\begin{array}{c}\text { Superfosfato Triplo } \\
\left(P_{2} \mathrm{O}_{5}-\mathrm{kg} / \mathrm{ha}\right)\end{array}$ & $\begin{array}{c}\text { Sulfato de } \\
\text { Zincolkg/ha })\end{array}$ \\
\hline 0 & 0 & 0 \\
1 & 200 & 15 \\
2 & 400 & 30 \\
\hline
\end{tabular}

Os solos estudados săo representativos das regiōes produtoras de soja do Triāngulo Mineiro e Alto Paranaíba, do Estado de Minas Gerais. A localização e a classificação dos mesmos, encontram-se na Tabela 2, e os resultados das análises químicas das suas amostras, aparecem na Tabela 3.

Tabela 2 - Classificação e Localização do Local de Coleta dos Solos.

\begin{tabular}{lll}
\hline Solo Classificação & Localização \\
\hline
\end{tabular}

1) LV Latossolo Vermelho Amarelo

PADAP (Programa de Assentamen to Dirigido do Alto Paranaibá), município de Rio Paranaíba. En trando pelo trevo de Rio Parā naíba, a caminho da Estação $\overline{E X}$ perimental desta cidade, a I $\mathrm{km}$ do trevo e $1 \mathrm{~km}$ da sede da referida Estação.

2) LEm Latossolo Vermelho Escuro textura mëdia

$\mathrm{km}$ 35, à margem esqueda da $B R$ 050, município de Uberaba.

3) LE Latossolo Vermelho Escuro

Margem direita da Rodovia Patrocínio-Ibiá, a $12 \mathrm{~km}$ de $\mathrm{Pa-}$ trocínio, município de Patrocínio. 
19.

Tabela 3 - Resultados da Análise Química de Amostras dos Solos Estu dados.

\begin{tabular}{|c|c|c|c|c|c|c|c|c|}
\hline \multirow{2}{*}{ Solo } & \multirow{2}{*}{$\begin{array}{c}\mathrm{pH} \text { em } \mathrm{H}_{2} \mathrm{O} \\
1: 2,5^{2}\end{array}$} & \multirow{2}{*}{$\begin{array}{l}\text { C } \\
\%\end{array}$} & \multicolumn{3}{|c|}{ Teor trocável em } & \multicolumn{2}{|c|}{ e.mg/lo0g de } & \multirow{2}{*}{$\frac{\text { terra }}{\mathrm{H}^{+}}$} \\
\hline & & & $\mathrm{PO}_{4} \equiv$ & $k^{+}$ & $\mathrm{Ca}^{2+}$ & $\mathrm{Mg}^{2+}$ & $\mathrm{Al}^{3+}$ & \\
\hline & \multicolumn{8}{|c|}{ Sem Calagem } \\
\hline LV & 4,9 & 2,04 & 0,009 & 0,12 & 0,16 & 0,05 & 0,66 & 7,84 \\
\hline LEm & 5,1 & 0,48 & 0,009 & 0,14 & 0,29 & 0,11 & 1,25 & 3,44 \\
\hline \multirow[t]{2}{*}{ LE } & 4,9 & 1,56 & 0,012 & 0,30 & 0,26 & 0,14 & 0,66 & 6,16 \\
\hline & \multicolumn{8}{|c|}{ Após Calagem } \\
\hline LV & 5,4 & 1,92 & 0,011 & 0,12 & 1,55 & 1,09 & 0,18 & 6,96 \\
\hline LEm & 6,6 & 0,45 & 0,015 & $0,0 \theta$ & 1.76 & 1,07 & 0,10 & 1,22 \\
\hline LE & 5,8 & 1,50 & 0,011 & 0,12 & 1,52 & 0,96 & 0,14 & 4,99 \\
\hline
\end{tabular}

Verifica-se, pela interpretação dos resultados anali ticos das amostras dos solos (Tabela 3), segundo CATANI e JACINTO (1974), que para o pH, os LE e LV apresentavam-se com acidez elevada e o LEm com acidez média. Após a calagem, os LE e LV apresentaram-se com acidez média e o LEm, com acidez fraca. Para carbono, os LE e LV mostraram um teor alto, e o LEm, baixo. Em relação ao fósfo ro, todos os solos apresentaram-se com teores baixos. Inicialmente, os solos apresentavam-se com teores médios de K. Após a calagem, os LE e LV passaram ê apresentar-se com teores médios e o LEm, baixo. Para o cálcio, os solos apresentaram-se com teores baixos, mesmo a- 
pós a calagem. Entretanto, os teores de magnésio que eram baixos inicialmente nos solos, passaram a altos, após a calagem. Inicialmen te, os teores de alumínio nos solos eram altos, passando, após a ca lagem, a baixos. Quanto à acidez total, esta era alta nos solos LE e LV e média no LEm. Após a calagem a acidez total no LV continuou alta, passando, entretanto, para média e baixa no LE e LEm, respectivamente.

A análise das amostras dos solos, apōs a calagem, para $2 \mathrm{n}$ extraivel com $\mathrm{H}_{2} \mathrm{SO}_{4} 0,025 \mathrm{~N}$ mais $\mathrm{HCl} 0,05 \mathrm{~N}$, conforme metodologia apresentada por PERKIN-ELMER (1973), revelou teores de 2,7:1,7 e 2,2 ppm para os LV, LEm e LE, respectivamente.

Os solos foram coletados superficialmente a uma profundidade média de $20 \mathrm{~cm}$. Previamente, antes da instalação do experi mento,e com base nos teores de alumínio, cálcio e magnésio trocáveis, foi feita uma calagem utilizando uma mistura de $\mathrm{CaO}_{3}+\mathrm{MgO}_{3}$, apresentando aproximadamente $31 \%$ de CaO e $21 \%$ de MgO (PIPAEMG, 1972).Após a calagem, os solos foram mantidos com um teor de umidade de cer ca de $40 \%$ da capacidade de saturação da amostra, por uma semana. To dos os tratamentos receberam uma adubação básica NK $120 \mathrm{~kg} / \mathrm{ha}$ de $N$ como sulfato de amônio e $50 \mathrm{~kg} /$ ha de $K_{2} 0$ como cloreto de potássio). Cada vaso recebeu $7 \mathrm{~kg}$ de terra. Para efeito de cálculo das dosagens dos nutrientes por vaso, considerou-se uma densidade aparente de 1,3 e uma profundidade de $20 \mathrm{~cm}$, para os 3 solos estudados. Com exceção do superfosfato triplo, os reagentes usados como fontes de 
nutrientes ou visando calagem foram de classificação química p.a.

0 plantio foi feito colocando-se 5 sementes por vaso. Durante o plantio, as sementes foram inoculadas com as estirpes SMS - 313 + SMS - 335 de Rhizobium japonicum cedidas pela Seção de Mirrobiologia do Solo do Instituto Agronómico de Campinas. Decorridos 5 dias após a germinação, foi realizado um desbaste, deixandoapenas 2 plantas por vaso.

Diariamente todos os tratamentos foram irrigados com ägua destilada. Visando evitar danos de uma irrigação excessiva, um sistema de coleta do excedente foi adaptado aos vasos.

A colheita foi realizada 43 dias após o plantio quan do todas as plantas se apresentavam no estágio de florescimento. A perte aérea foi cortada ao nível da superfície do solo. Para as pos teriores análises químicas, a parte aérea foi dividida em hastes, fo lhas velhas e novas. As raízes das plantas, separadas da terra dos vasos por fortes jatos de água, foram acondicionadas em sacos de pa pel, da mesma maneira como as diferentes porções da parte aérea. Os nódulos das raizes também foram coletados.

0 material vegetal e os nódulos foram secos em estufa de circulação forçada, a $60-70^{\circ} \mathrm{C}$, até peso constante, e posterior mente pesados em balança analítica. Após pesagens, o material vegetal foi moído em moínho Wiley e conservado em sacos de papel impermeável. 
conforme métodos descritos por SARRUGE e HAAG (1974).

Os resultados obtidos foram analisados estatisticamente. 
23.

\section{RESULTADOS E DISCUSSÃO}

\section{1 - Produção de Matéría Seca: Raízes, Parte Aérea e Nödulos}

As anälises da variância dos dados relativos aos pesos da matéria seca das rafzes, parte aérea e nódulos são apresenta das de forma resumida na Tabela 4. Observou-se que, para matéria se ca das raízes e nódulos, houve efeito de solos, fósforo e interação solos $x$ fósforo. Entretanto, para matéría seca da parte aérea, observou-se efeito somente de solos e fósforo.

As produções de matéria seca das rafzes e parte aérea, em função das doses de fósforo e solos, são apresentadas nas Tabelas 5 e 6 . 
Tabela 4 - Resumo das Anālises da Variância dos Dados Relativos aos Pesos de Matéria Seca das Raízes, Parte Aérea e Nódulos.

\begin{tabular}{|c|c|c|c|c|}
\hline \multirow{2}{*}{$\begin{array}{l}\text { Causa de } \\
\text { Varlação }\end{array}$} & \multirow{2}{*}{ G.L. } & \multicolumn{3}{|c|}{ Q.M. } \\
\hline & & Raízes & Parte aérea & Nódulos \\
\hline Solos & 2 & $2,691395^{* * *}$ & $5,160860^{* *}$ & $0,105970^{* 6 \%}$ \\
\hline$P$ & 2 & $39,687621^{* \%}$ & $547,473650^{* 2 *}$ & $0,689455^{\% \%}$ \\
\hline$Z_{n}$ & 2 & 0,095731 & 1,234172 & 0,004598 \\
\hline Solos $\times P$ & 4 & $0,318948 \%$ & 0,613188 & $0,047236^{\% \%}$ \\
\hline Solos $\times \mathrm{Zn}$ & 4 & 0,216581 & 1,185272 & 0,003059 \\
\hline$P \times Z n$ & 4 & 0,210251 & 0,845979 & 0,002364 \\
\hline Solos $\times P \times Z n$ & 8 & 0,179310 & 1,533692 & 0,005000 \\
\hline Tratamentos & 26 & $3,437195^{\% * \%}$ & $43,484020 \%$ & $0,071180^{208 \%}$ \\
\hline Resíduo & 27 & 0,104809 & 1,113137 & 0,008110 \\
\hline C.V. & & $10,77 \%$ & $11,97 \%$ & $46,82 \%$ \\
\hline
\end{tabular}

Tabela 5 - Peso de Matéria Seca das Raízes, em g/vaso, em Função Das Doses de Fósforo e Solos.

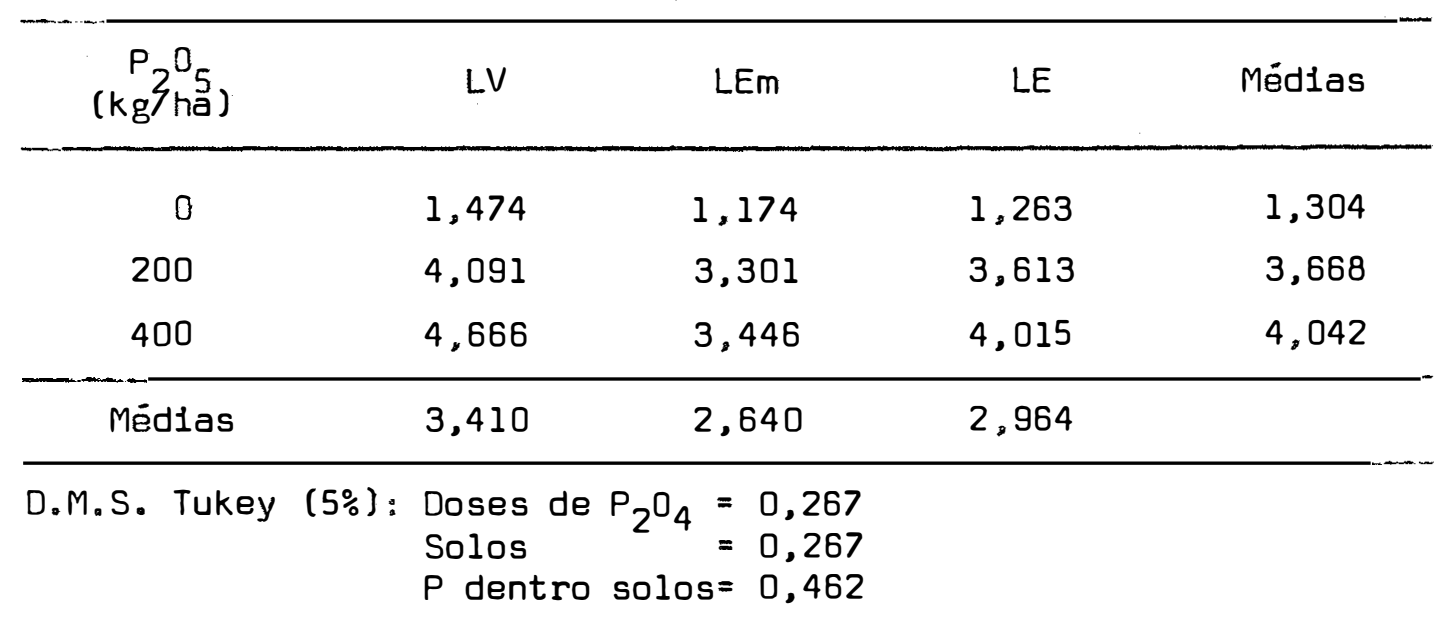


Tabela 6 - Peso de Matéria Seca da Parte Aérea, em g/vaso, em Função das Doses de Fósforo e Solos.

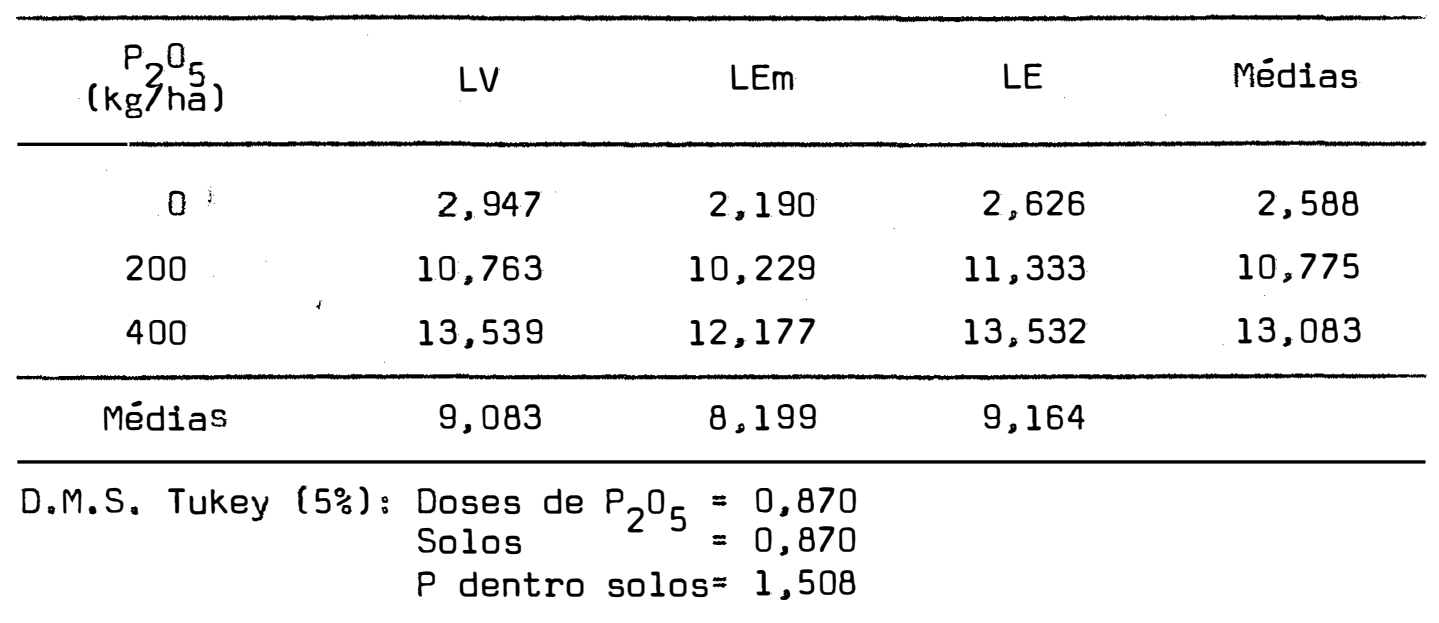

Pode-se observar na Tabela 5 que os acréscimos de produção de raízes, em função das doses de fósforo, tiveram a mesma tendência nos três solos estudados. Entretanto, entre eles a res posta foi marcante no LV. Tanto no LE, quanto no LEm, não houve diferença entre as produções nas doses 200 e $400 \mathrm{~kg}$ de $\mathrm{P}_{2} \mathrm{O}_{5} /$ ha. Quando se analisa a Tabela 6, verifica-se que, para produção de matéria seca da parte aérea, os solos se comportaram semelhantemente, ocorrendo as maiores respostas no LV e LE, os quais não se diferenciaram estatisticamente.

As respostas à fertilização fosfatada, verificadas neste trabalho pelos aumentos de produção de matéría seca das raízes e parte aérea, são concordantes com os resultados obtidos por HOWELL (1954). FLETCHER e KURTZ (1964) e GOEPFERT e FREIRE (1972). 
Não se encontraram respostas à aplicação de zinco para produção de matéria seca de raízes e parte aérea. A falta de res postas à aplicação desse micronutriente, foram verificadas também por SALAKO et alii (1975). MASCARENHAS et alii (1977), explicando a ação ineficiente da fertilização com micronutrientes para a cultura da soja, verificada por diversos autores, sugere que isto se deve, provavelmente, ao fato dos calcários usados como corretivos, superfosfato simples e triplo, apresentarem teores suficientes de micronutrientes para o bom desenvolvimento das plantas. Deve-se levar em consideração que, neste trabalho, foram utilizados superfosfato tri plo como fonte de fósforo e água destilada na irrigação.

Os pesos dos nódulos secos em função das doses de fós foro e solos, encontram-se na Tabela 7.

Tabela 7 - Pesos dos Nódulos Secos, em g/vaso, em Função das Doses de Fósforo e Solos.

\begin{tabular}{|c|c|c|c|c|}
\hline 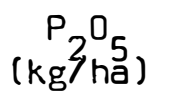 & LV & LEm & LE & Médias \\
\hline 0 & 0,003 & 0,001 & 0,001 & 0,002 \\
\hline 200 & 0,250 & 0,177 & 0,121 & 0,183 \\
\hline 400 & 0,506 & 0,476 & 0,196 & 0,393 \\
\hline Médias & 0,253 & 0,218 & 0,106 & \\
\hline
\end{tabular}


Pela Tabela 7 verifica-se que a nodulação nos solos LV e LEm aumentou com a elevação das doses de fósforo. No LE, no en tanto, um acréscimo na nodulação ocorreu somente entre as doses 03 200 ou $400 \mathrm{~kg}$ de $\mathrm{P}_{2} \mathrm{O}_{5} / \mathrm{ha}$. Este efeito estimulante do fósforo na nodulação já foi também observado por diversos autores, como FLETCHER e KURTZ (1964), MOOY e PESEK (1966), GOEPFERT (1971), GOEPFERT e FREI RE (1972) e PEREIRA (1972).

\section{2 - Concentração de Nutrientes em Função dos Níveis de Fósforo, Zinco e Solos}

\subsection{1 - Concentração de nitrogênio}

Pelas análises da variância, Tabela 8, observou-se que, para hastes, houve efeito de solos, fósforo, interações solos $x$ fósforo e fósforo $x$ zinco. Tanto para folhas velhas, quanto para novas, houve efeito apenas de solos e fósforo.

As concentrações de nitrogênio nas hastes, folhas ve lhas e novas, em função das doses de fósforo e solos são apresentadas nas Tabelas 9, 10 e 11 . 
Tabela 8 - Resumo das Análises da Variência das Concentrações de Ni trogênio na Matëría Seca das Hastes, Folhas Velhas e Novas.

\begin{tabular}{|c|c|c|c|c|}
\hline \multirow{2}{*}{$\begin{array}{l}\text { Causa de } \\
\text { Variação }\end{array}$} & \multirow{2}{*}{ G.L. } & \multicolumn{3}{|c|}{ Q.M. } \\
\hline & & Hastes & Folhas Velhas & Folhas Novas \\
\hline Solos & 2 & $0,126206^{* * *}$ & $2,103140^{2 * *}$ & $1,304656^{* 6 \% 5}$ \\
\hline$P$ & 2 & $25,989340 * *$ & $31,025395^{* \%}$ & $10,718806^{*}$ \\
\hline $\mathrm{Zn}$ & 2 & 0,046667 & 0,074751 & 0,195116 \\
\hline Solos $\times P$ & 4 & $0,133893 \%$ & 0,293629 & 0,159524 \\
\hline Solos $\times \mathrm{Zn}$ & 4 & 0,016113 & 0,138860 & 0,115227 \\
\hline$P \times Z n$ & 4 & $0,055304 \%$ & 0,052732 & 0,174519 \\
\hline Solos $\times P \times Z n$ & 8 & 0,017857 & 0,096443 & 0,080445 \\
\hline Tratamentos & 26 & $2,049559 *$ & $2,658422^{* * *}$ & $1,033761^{* 28 \%}$ \\
\hline Resíduo & 27 & 0,019805 & 0,145757 & 0,082173 \\
\hline C.V. & & $8,45 \%$ & $11,49 \%$ & $7,73 \%$ \\
\hline
\end{tabular}

Tabela 9 - Concentrações de Nitrogênio, em \%, nas Hastes em Função das Doses de Fósforo e Solos.

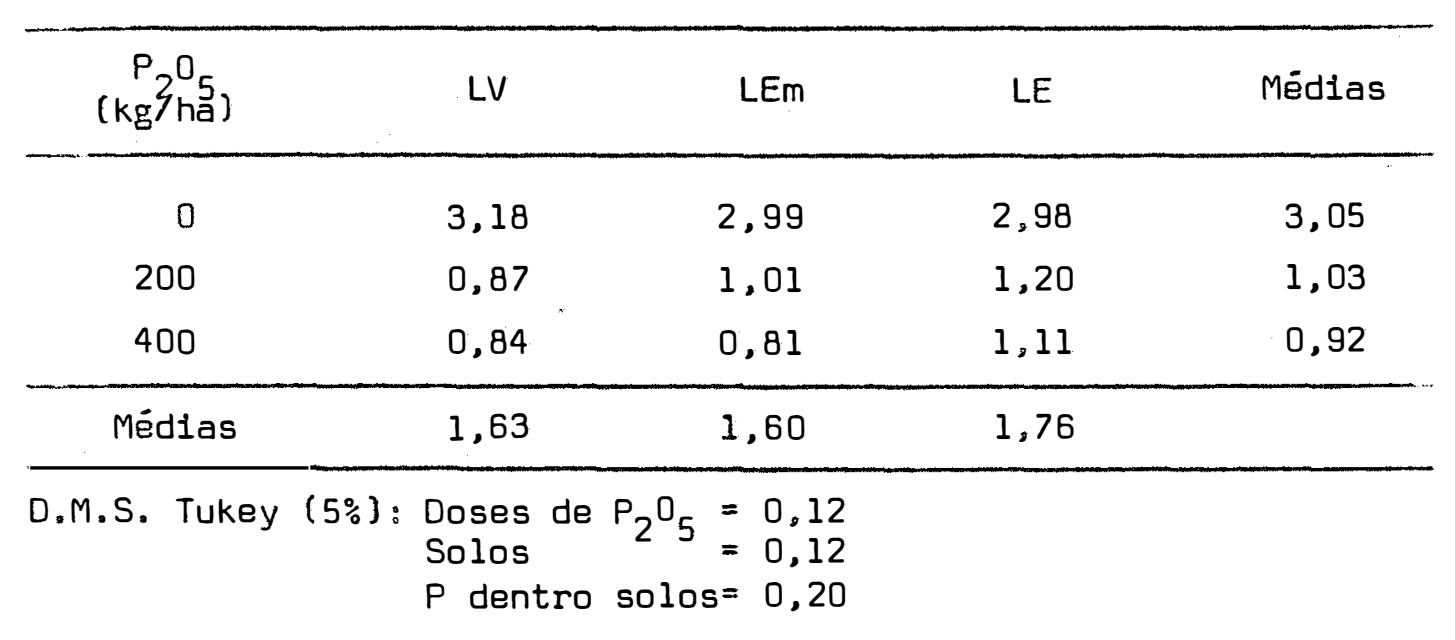


Tabela 10 - Concentrações de Nitrogênio, em \%, nas Folhas Velhas em Função das Doses de Fósforo e Salos.

\begin{tabular}{|c|c|c|c|c|}
\hline$\left.{ }_{\left(k^{2}\right.}{ }^{P_{h}}{ }^{\circ}\right)$ & LV & LEm & LE & Médias \\
\hline 0 & 4,79 & 4.74 & 4,97 & 4,83 \\
\hline 200 & 2,53 & 2,23 & 3,28 & 2,68 \\
\hline 400 & 2,22 & 2,26 & 2,89 & 2,46 \\
\hline Médias & 3,18 & 3,08 & 3,71 & \\
\hline
\end{tabular}

Tabela 11 - Concentrações de Nitrogênio, em \%, nas Folhas Novas em Função das Doses de Fósforo e Solos.

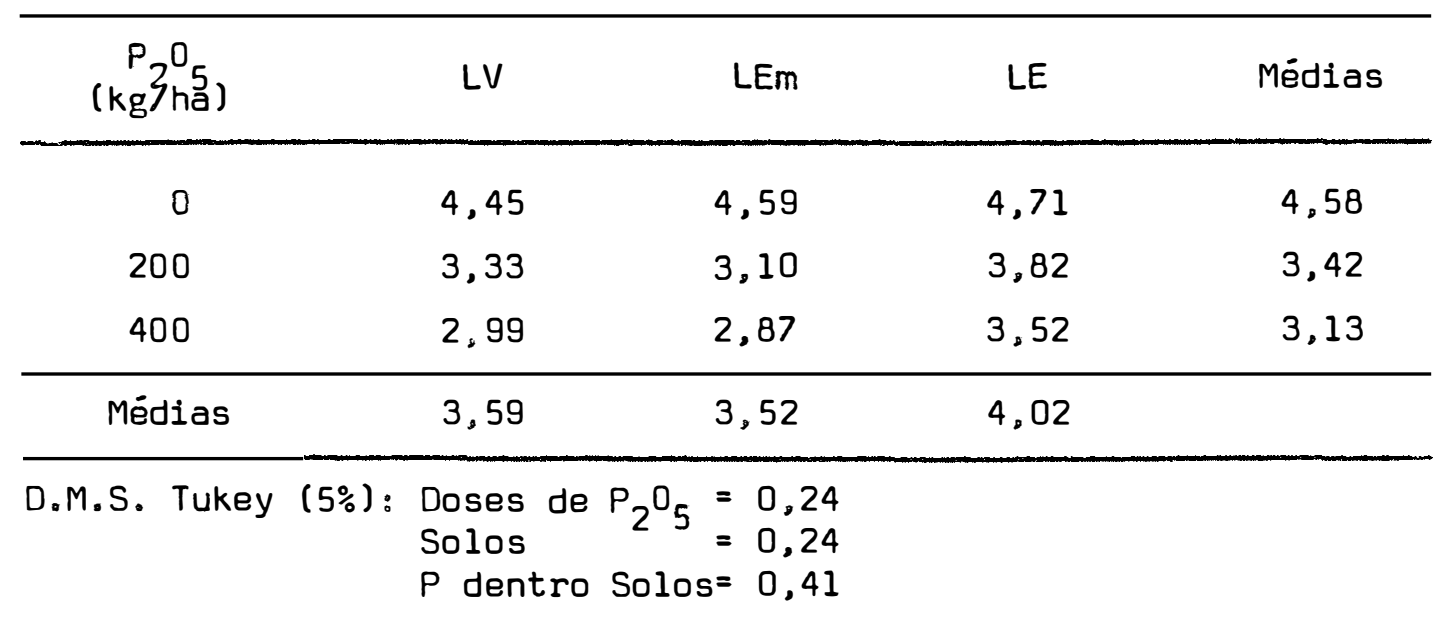


Verifica-se, pela Tabela 9, que as concentrações de nitrogênio nas hastes decresceram da mesma maneira nos LV e LE, pela adubação fosfatada. No LEm, entretanto, houve decréscimo também quando a dose foi elevada de 200 para $400 \mathrm{~kg}$ de $P_{2} \mathrm{O}_{5} /$ ha. Quanto às concentrações de nitrogénio nas folhas velhas e novas, apresentadas nas Tabelas 10 e 11 , observa-se tambëm uma diminuição das concentra ções de nitrogênio pela adubação com fósforo em qualquer dose, para os três solos. Entre estes, as concentrações maiores ocorreram no LE. - qual diferiu dos LV e LEm. As reduções verificadas pela fertiliza ção fosfatada é concordante com a literatura: WEBER e CALDWELL (1962) e CONROY e LAMBE (1962) observaram efeito antagônico entre o fósforo e nitrogênio. Entretanto, os decréscimos das concentrações de nitrogènio pela elevação da dose 0 para 200 ou $400 \mathrm{~kg}$ de $P_{2} O_{5} / \mathrm{ha}$, podem ser atribuidos a um efeito de diluição, já que, devido à pobreza em fósforo nestes solos, ocorreu uma drástica redução no cres cimento quando o mesmo não foi fornecido.

A Tabela 12 apresenta as concentrações de nitrogênio nas hastes, em função das doses de zinco e fósforo. 
Tabela 12 - Concentrações de Nitrogênio, em \%, nas Hastes, em Função das Doses de Zinco e Fósforo.

\begin{tabular}{|c|c|c|c|c|}
\hline \multirow{2}{*}{$\begin{array}{l}\text { Sulfato } \\
\text { de zinco } \\
\text { (kg/ha) }\end{array}$} & \multicolumn{3}{|c|}{$\mathrm{P}_{2} \mathrm{O}_{5}$ (kg/ha) } & \multirow{2}{*}{ Médias } \\
\hline & 0 & 200 & 400 & \\
\hline 0 & 3,12 & 0,91 & 0,94 & 1,66 \\
\hline 15 & 3,09 & 1.17 & 0,90 & 1,72 \\
\hline 30 & 2,95 & 1,00 & 0,92 & 1,62 \\
\hline Médias & 3,05 & 1,03 & 0,92 & \\
\hline \multicolumn{5}{|c|}{$\begin{aligned} \text { D.M.S. Tukey }(5 \%): & \text { Doses de } \mathrm{P}_{2} \mathrm{O}_{5}=0,12 \\
& \text { Doses de Sulfato de Zinco = } 0,12 \\
& \mathrm{Zn} \text { dentro } \mathrm{P}=0,20 \\
& P \text { dentro } \mathrm{Zn}=0,20\end{aligned}$} \\
\hline
\end{tabular}

Observa-se na Tabela 12 uma elevação na concentração de nitrogênio nas hastes quando a dose de sulfato de zinco passou de 0 para $15 \mathrm{~kg} / \mathrm{ha}$, na presença de $200 \mathrm{~kg}$ de $\mathrm{P}_{2} \mathrm{O}_{5} / \mathrm{ha}$. Para as doses 0 e $400 \mathrm{~kg}$ de $\mathrm{P}_{2} \mathrm{O}_{5} / \mathrm{ha}$, não foi observado efeito da adubação com zinco. Esta elevação na concentração de nitrogênio poderia ser atribuída . provavelmente, a uma melhoria do estado nutricional da planta pela adição do zinco, proporcionando condições para uma melhor absorção de nutrientes, apesar da fertilização com este micronutriente não ter sido traduzida em forma de aumento de matéria seca. Efeitos semelhantes foram observados também para as concentrações de nitrogènio nas folhas novas, como pode ser observado na Tabela 13. 
Tabela 13 - Concentrações de Nitrogênio, em \%, nas Folhas Novas, em Função das Doses de Zinco e Fósforo.

\begin{tabular}{|c|c|c|c|c|}
\hline \multirow{2}{*}{$\begin{array}{l}\text { Sulfato } \\
\text { de Zinco } \\
\text { (kg/ha) }\end{array}$} & \multicolumn{3}{|c|}{$\mathrm{P}_{2} \mathrm{O}_{5}(\mathrm{~kg} / \mathrm{ha})$} & \multirow{2}{*}{ Médias } \\
\hline & 0 & 200 & 400 & \\
\hline 0 & 4,60 & 3,17 & 3,00 & 3,59 \\
\hline 15 & 4,52 & 3,68 & 3,10 & 3,77 \\
\hline 30 & 4,63 & 3,39 & 3,29 & 3,77 \\
\hline Médias & 4,58 & 3,41 & 3,13 & \\
\hline D.M.S. Tuk & $\begin{array}{l}\text { Doses } \\
\text { Doses } \\
\text { Zn der } \\
P \text { dent }\end{array}$ & $\begin{array}{l}=0,2 \\
\text { ato } d \\
=0,2 \\
=0,2\end{array}$ & $=0.24$ & \\
\hline
\end{tabular}

\section{2 .2 - Concentração de fösforo}

As anälises da variância, de forma resumida, das con centrações de fósforo nas hastes, folhas velhas e novas, são apresentadas na Tabela 14. Observou-se para hastes, efeito apenas de so los e fósforo. Além deste, verificou-se também, para folhas velhas e novas, o das interações fósforo $\times$ zinco e solos $x$ fósforo, respec tivamente.

Nas Tabelas. 15, 16 e 17 são apresentadas as concentrações de fósforo nas hastes, folhas velhas e novas, respectivamen te, em função das doses de fósforo e solos. 
Tabela 14 - Resumo das Anälises da Variância das Concentrações de Fösforo na Matéría Seca das Hastes, Folhas Velhas e Novas.

\begin{tabular}{|c|c|c|c|c|}
\hline \multirow{2}{*}{$\begin{array}{l}\text { Causa de } \\
\text { Variação }\end{array}$} & \multirow{2}{*}{ G.L. } & \multicolumn{3}{|c|}{ Q.M. } \\
\hline & & Hastes & Folhas Velhas & Folhas Novas \\
\hline Solos & 2 & $0,001015^{34 x}$ & $0,002533 * *$ & $0,002540 * \%$ \\
\hline$P$ & 2 & $0,000959 * *$ & $0,006080 *$ & $0,009310^{2 * \%}$ \\
\hline $\mathrm{Zn}$ & 2 & 0,000035 & 0,000146 & 0,000225 \\
\hline Solos $\times P$ & 4 & 0,000150 & 0,000644 & $0,001839 *$ \\
\hline Solos $\times \mathrm{Zn}$ & 4 & 0,000051 & 0,000168 & 0,000071 \\
\hline$P \times Z n$ & 4 & 0,000138 & $0,000910 \%$ & 0,000679 \\
\hline Solos $\times P \times Z n$ & 8 & 0,000043 & 0,000096 & 0,000253 \\
\hline Tratamentos & 26 & $0,000220 *$ & $0,000968 *$ & $0,001405 \%$ \\
\hline Resíduo & 27 & 0,000080 & 0,000283 & 0,000426 \\
\hline C.V. & & $16,26 \%$ & $19,18 \%$ & $12,76 \%$ \\
\hline
\end{tabular}

Tabela 15 - Concentrações de Fósforo, em \%, nas Hastes em Função das Doses de Fósforo e Solos.

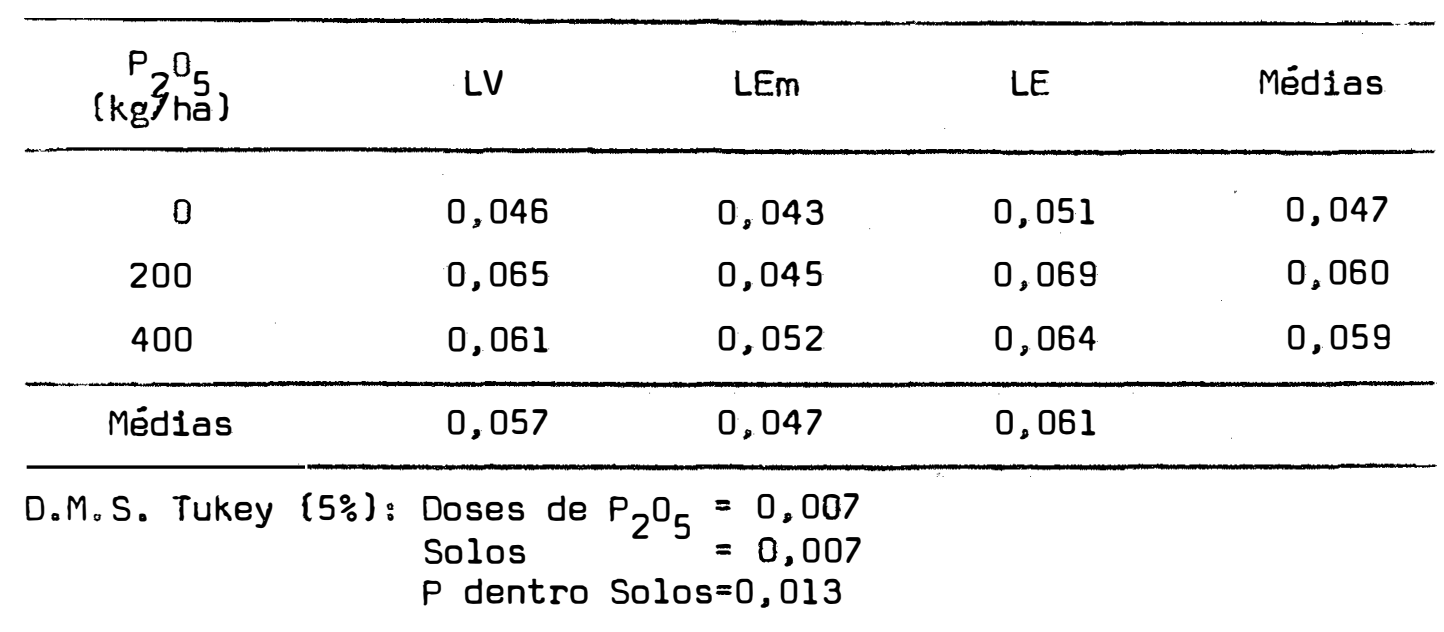


Tabela 16 - Concentrações de Fösforo, em \%, nas Folhas Velhas em Fun ção das Doses de Fösforo e Solos.

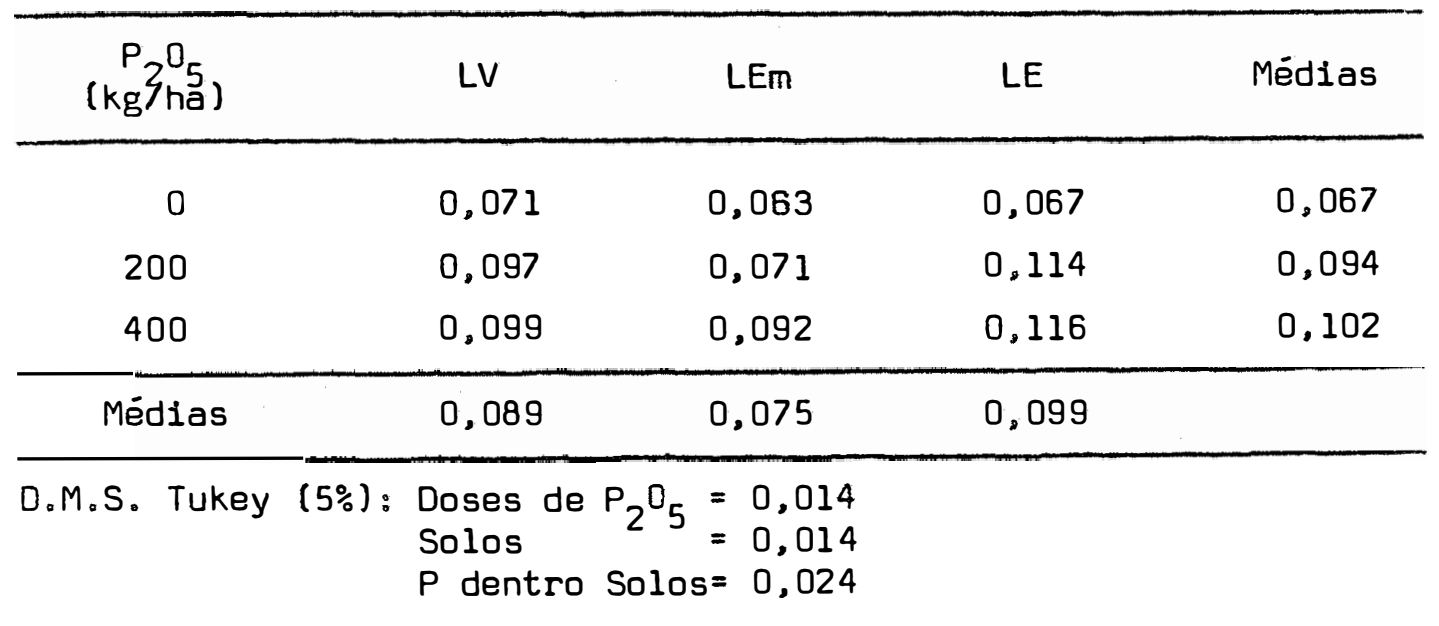

Tabela 17 - Concentrações de Fósforo, em \% nas Folhas Novas em Fun ção das Doses de Fósforo e Solos.

\begin{tabular}{|c|c|c|c|c|}
\hline$\left(\mathrm{kg}^{2} \mathrm{P}^{\mathrm{O}_{5}}\right)$ & LV & LEm & LE & Médias \\
\hline 0 & 0,140 & 0,141 & 0,139 & 0,140 \\
\hline 200 & 0,171 & 0,124 & 0,185 & 0,160 \\
\hline 400 & 0,185 & 0,181 & 0,191 & 0,186 \\
\hline Médias & 0,165 & 0,149 & 0,172 & \\
\hline
\end{tabular}

D.M.S. Tukey (5\%): Doses de $P_{2} \mathrm{O}_{5}=0,017$

$P$ dentro Solos $=0,030$ 
Verifica-se, de modo geral, pelas Tabelas 15, 16 e 17. uma elevação da concentração de fósforo, nas diversas partes da plan ta, pela adubação fosfatada, o que se faz notar, principalmente entre as doses 0 e $400 \mathrm{~kg}$ de $\mathrm{P}_{2} \mathrm{O}_{5} / \mathrm{ha}$. Entre as doses 200 e $400 \mathrm{~kg}$ de $\mathrm{P}_{2} \mathrm{O}_{5}$ /ha, verifica-se acréscimo somente nas folhas novas, no LEm. Es ta elevação dos teores de fósforo no tecido vegetal pela adição des te nutriente ao meio, já foi observada também por WEBER e CALDWELL (1962), FLETCHER e KURTZ (1964) e PEREIRA (1972)。

Na Tabela 18 são apresentadas as concentrações de fós foro nas folhas velhas, em função das doses de zinco e fósforo.

Tabela 18 - Concentrações de Fösforo, em \%, nas Folhas Velhas em Fun ção das Doses de Zinco e Fósforo.

\begin{tabular}{|c|c|c|c|c|}
\hline \multirow{2}{*}{$\begin{array}{l}\text { Sulfato } \\
\text { de zinco } \\
\text { (kg/ha) }\end{array}$} & \multicolumn{3}{|c|}{$\mathrm{P}_{2} \mathrm{O}_{5}(\mathrm{~kg} / \mathrm{ha})$} & \multirow{2}{*}{ Médias } \\
\hline & 0 & 200 & 400 & \\
\hline 0 & 0,080 & 0,084 & 0,096 & 0,087 \\
\hline 15 & 0,062 & 0,098 & 0,096 & 0,085 \\
\hline 30 & 0,059 & 0,100 & 0,115 & 0,091 \\
\hline Médias & 0,067 & 0,094 & 0,102 & \\
\hline \multicolumn{5}{|c|}{$\begin{aligned} \text { D.M.S. Tukey }(5 \%): & \text { Doses de } \mathrm{P}_{2} \mathrm{O}_{5}=0,014 \\
& \text { Doses de Sulfato de Zinco }=0,014 \\
& \mathrm{Zn} \text { dentro } P=0,024 \\
& P \text { dentro } \mathrm{Zn}=0,024\end{aligned}$} \\
\hline
\end{tabular}


Pela análise da Tabela 18, pode-se verificar que os acréscimos das concentrações de fósforo pela fertilização fosfatada, tornaram-se maiores à medida que as doses de zinco foram elevadas. Embora não alcançasse significância quando não houve adubação fosfatada, as concentrações de fósforo tenderam a diminuir pelo aumento das doses de zinco, sugerindo um antagonismo entre estes elementos, bastante conhecido. As tendências de aumento das concentrações de fósforo, promovidas pela fertilização com zinco, poderiam ser atribuídas, provavelmente, como já anteriormente mencionado para as concentrações de nitrogênio, a uma melhoria do estado nutricional da planta, proporcionando assim, condições para uma melhor absorção de nutrientes.

\section{2 .3 - Concentração de potássio}

Verifica-se pela Tabela 19 que, para as hastes, houve efeito de solos, fósforo, zinco e interações solos $x$ fósforo e solos $\times$ fósforo $\times$ zinco. Para folhas velhas, houve efeito de solos, fósforo e interações fósforo $x$ solos e fósforo $\times$ zinco e para folhas novas, somente o efeito de fósforo.

Nas Tabelas 20, 21 e 22 são encontrados os dados relativos às concentrações de potássio nas hastes, folhas velhas e no vas, respectivamente, em função das doses de fósforo e solos. 
Tabela 19 - Resumo das Análises da Variāncia das Concentraçōes de Potássio na Matéria Seca das Hastes. Folhas Velhas e No vas.

\begin{tabular}{|c|c|c|c|c|}
\hline \multirow{2}{*}{$\begin{array}{l}\text { Causa de } \\
\text { Variação }\end{array}$} & \multirow{2}{*}{ G.L. } & \multicolumn{3}{|c|}{ Q.M. } \\
\hline & & Hastes & Folhas Velhas & Folhas Novas \\
\hline Solos & 2 & $0,367113^{* * *}$ & $0,591157 *$ & 0,056273 \\
\hline$P$ & 2 & $0,547813 * \%$ & $0,154413 \%$ & $0,158017 \%$ \\
\hline $2 n$ & 2 & $0,039368 *$ & 0,015791 & 0,000773 \\
\hline Solos $\times \mathrm{P}$ & 4 & $0,105282 \%$ & $0,071579 \approx$ & 0,035646 \\
\hline Solos $\times \mathrm{Zn}$ & 4 & 0,013629 & 0,011240 & 0,007277 \\
\hline$P \times Z n$ & 4 & 0,010737 & $0,045362 *$ & 0,040613 \\
\hline Solos $\times P \times Z n$ & 8 & $0,034182 \%$ & 0,012846 & 0,017278 \\
\hline Tratamentos & 26 & $0,103871 \%$ & $0,082239 \% \%$ & 0,034711 \\
\hline Resíduo & 27 & 0,008809 & 0,011349 & 0,020137 \\
\hline C.V. & & $9,77 \%$ & $9.58 \%$ & $8,41 \%$ \\
\hline
\end{tabular}

Tabela 20 - Concentrações de Potássio, em \% nas Hastes, em Função das Doses de Fósforo e Solos.

\begin{tabular}{|c|c|c|c|c|}
\hline${ }_{(\mathrm{kg}}^{\mathrm{P} \mathrm{O}_{5}}$ & LV & LEm & LE & Médias \\
\hline 0 & 0,72 & 0.77 & 0,82 & 0,77 \\
\hline 200 & 1,23 & 0,80 & 1,30 & 1,11 \\
\hline 400 & 1,03 & 0,84 & 1.13 & 1,00 \\
\hline Médias & 0,99 & 0,80 & 1,08 & \\
\hline
\end{tabular}


Tabela 21 - Concentrações de Potássio, em \%, nas Folhas Velhas, em Função das Doses de Fósforo e Solos.

\begin{tabular}{|c|c|c|c|c|}
\hline$\left.\left.{ }_{(\mathrm{kg}}{ }^{\mathrm{P}} \mathrm{C}_{5}\right)\right)$ & LV & LEm & LE & Médias \\
\hline 0 & 1,20 & 1,10 & 1,24 & 1,18 \\
\hline 200 & 1,28 & 0,85 & 1,32 & 1,15 \\
\hline 400 & 1,17 & 0,76 & 1.09 & 1,01 \\
\hline Médias & 1,22 & 0,90 & 1,22 & \\
\hline
\end{tabular}

Tabela 22 - Concentrações de Potássio, em \%, nas Folhas Novas, em Função das Doses de Fósforo e Solos.

\begin{tabular}{|c|c|c|c|c|}
\hline$\left.(\mathrm{kg}\}_{\mathrm{ha}}^{\mathrm{O}}\right)$ & LV & LEm & LE & Médias \\
\hline 0 & 1,56 & 1,57 & 1,60 & 1,58 \\
\hline 200 & 1,81 & 1,59 & 1,86 & 1,75 \\
\hline 400 & 1.76 & 1,71 & 1,72 & 1,73 \\
\hline Médias & 1,71 & 1,62 & 1,73 & \\
\hline
\end{tabular}


Pode-se observar para hastes, Tabela 20, que as concentrações de potássio variaram diferentemente dentro dos solos, em função dos níveis de fósforo aplicados. Somente no LEm, não foi observado decréscimo na concentração de potássio pelo aumento de 200 para $400 \mathrm{~kg}$ de $\mathrm{P}_{2} \mathrm{O}_{5} /$ ha. Para folhas velhas, Tabela 21 , observa-se um decréscimo das concentrações de potássio pela elevação de 200 para $400 \mathrm{~kg}$ de $\mathrm{P}_{2} \mathrm{O}_{5} / \mathrm{ha}$. Estes efeitos se evidenciaram no LE. Pela Tabela 22, verifica-se apenas o efeito do fósforo, aumentando a concentração de potássio nas folhas novas.

Quando se comparam as concentrações de potássio nas diversas partes da planta, Tabela 23, observa-se uma tendência de decréscimo nas folhas velhas e acréscimo nas folhas novas e hastes pela adubação com fósforo, sendo mais evidenciado quando se comparam as doses $\mathrm{O}$ e $400 \mathrm{~kg}$ de $\mathrm{P}_{2} \mathrm{O}_{5} / \mathrm{ha}$. Isto seria devido, provavelmente, a um maior crescimento da planta pela fertilização fosfatada. provocando assim uma translocação do potássio dentro da mesma, numa tentativa de suprir, com este nutriente, as regiões em crescimento. Este efeito sugere que a disponibilidade do potássio no solo não se encontrava à altura de atender às demandas da planta, ou que esta não apresentou condições de absorvê-lo à medida de suas necessidades.

Pela Tabela 24 verifica-se o efeito das doses de zin co promovendo um aumento da concentração de potássio nas hastes. 
Tabela 23 - Concentrações de Potássı,o, em \%, em Função das Diferentes Partes da Planta e Doses de Fósforo.

\begin{tabular}{rccc}
\hline $\begin{array}{r}\mathrm{P}_{2} \mathrm{O}_{5} \\
\left(\mathrm{~kg} \mathrm{~h}^{2}\right)\end{array}$ & Folhas Velhas & Hastes & Folhas Novas \\
\hline 0 & 1,18 & 0,77 & 1,58 \\
400 & 1,15 & 1,11 & 1,75 \\
400 & 1,01 & 1,00 & 1,73 \\
\hline
\end{tabular}

Tabela 24 - Concentrações de Potássio, em \%, nas Hastes, em Função das Doses de Zinco e Solos.

\begin{tabular}{ccccc}
\hline $\begin{array}{c}\text { Sulfato } \\
\text { de Zinco } \\
\text { (kg/ha) }\end{array}$ & LV & LEm & LE & Médias \\
\hline 0 & 1,01 & 0,76 & 1,00 & 0,92 \\
15 & 0,94 & 0,82 & 1,08 & 0,95 \\
30 & 1,03 & 0,84 & 1,17 & 1,01 \\
\hline Médias & 0,99 & 0,81 & 1,08 & \\
\hline D.M.S. Tukey (5\%): Doses de Sulfato de Zinco & $=0,08$ \\
& $\begin{array}{l}\text { Solos } \\
\text { Zn dentro Solos }\end{array}$ & 0,08 \\
& $=0,13$
\end{tabular}

Na Tabela 25 são apresentadas as concentraçöes de po tássio nas folhas velhas em função das doses de zinco e fósforo. 
Tabela 25 - Concentraçōes de Potássio, em \%, nas Folhas Velhas, em Função das Doses de Zinco e Fósforo.

\begin{tabular}{|c|c|c|c|c|}
\hline \multirow{2}{*}{$\begin{array}{l}\text { Sulfato } \\
\text { de Zinco } \\
\text { (kg/ha) }\end{array}$} & \multicolumn{3}{|c|}{$\mathrm{P}_{2} \mathrm{O}_{5}$ (kg/ha) } & \multirow{2}{*}{ Médias } \\
\hline & 0 & 200 & 400 & \\
\hline 0 & 1,20 & 1,14 & 0,91 & 1,08 \\
\hline 15 & 1,23 & 1,10 & 0,99 & 1,11 \\
\hline 30 & 1,10 & 1,21 & 1,12 & 1,14 \\
\hline Mëdias & 1.18 & 1,15 & 1,01 & \\
\hline D.M.S. Tukey $(5 \%)$ : & $\begin{array}{l}\text { Doses d } \\
\text { Doses d } \\
Z n \text { dent } \\
P \text { dentr }\end{array}$ & fo de & $\begin{array}{l}0,09 \\
0,09 \\
0,15 \\
0,15\end{array}$ & \\
\hline
\end{tabular}

A análise da Tabela 25 sugere, como já discutido para as concentraçōes de nitrogênio e fósforo, uma importāncia para a adição de zinco quando a planta está suprida de fósforo, pois, como pode ser verificado, parece que esta fertilização tende a promover em determinados casos, uma maior absorção de nutrientes, como o nitrogênio e fósforo já citados, e o potássio neste caso. O aumento da concentração de potássio ocorreu somente entre as doses 0 e $30 \mathrm{~kg}$ de $\mathrm{ZnSO}_{4}$ / ha na dose de $400 \mathrm{~kg}$ de $\mathrm{P}_{2} \mathrm{O}_{5} / \mathrm{ha}$. 


\section{2 .4 - Concentração de Cālcio}

As anālises da variância das concentrações de cálcio nas hastes, folhas velhas e novas, são apresentadas na Tabela 26 em forma resumida. Verificou-se que, para as hastes, houve efeito de solos e fósforo. Para folhas velhas, houve efeito de solos e intera ção solos $x$ fósforo e para folhas novas, efeito de fósforo e zinco.

Tabela 26 - Resumo das Análises da Variância das Concentrações de Cálcio na Matéría Seca das Hastes. Folhas Velhas e Novas.

\begin{tabular}{|c|c|c|c|c|}
\hline \multirow{2}{*}{$\begin{array}{l}\text { Causa de } \\
\text { Variação }\end{array}$} & \multirow{2}{*}{ G.L. } & \multicolumn{3}{|c|}{ Q.M. } \\
\hline & & Hastes & Folhas Velhas & Folhas Novas \\
\hline Solos & 2 & $0,028229 *$ & $0,124772 * \%$ & 0,000091 \\
\hline$P$ & 2 & $0,199651 \%$ & 0,009739 & $0,087202 * *$ \\
\hline$Z n$ & 2 & 0,004357 & 0,007606 & $0,012091 *$ \\
\hline Solos $\times P$ & 4 & 0,008651 & $0,042269 *$ & 0,004887 \\
\hline Solos $\times \mathrm{Zn}$ & 4 & 0,003365 & 0,023677 & 0,004518 \\
\hline$P \times Z n$ & 4 & 0,001329 & 0,024002 & 0,002029 \\
\hline Solos $\times P \times Z n$ & 8 & 0,001083 & 0,025200 & 0,005849 \\
\hline Tratamentos & 26 & $0,020251 * \%$ & $0,032524 \%$ & $0,011204 \%$ \\
\hline Resíduo & 27 & 0,004001 & 0,013187 & 0,003398 \\
\hline C.V. & & $10,68 \%$ & $8,68 \%$ & $6,86 \%$ \\
\hline
\end{tabular}


As concentrações de cálcio nas diversas partes da planta, em função das doses de fósforo e solos, acham-se nas Tabelas 27,28 e 29 .

Tabela 27 - Concentrações de Cälcio, em \%, nas Hastes, em Função das Doses de Fósforo e Solos.

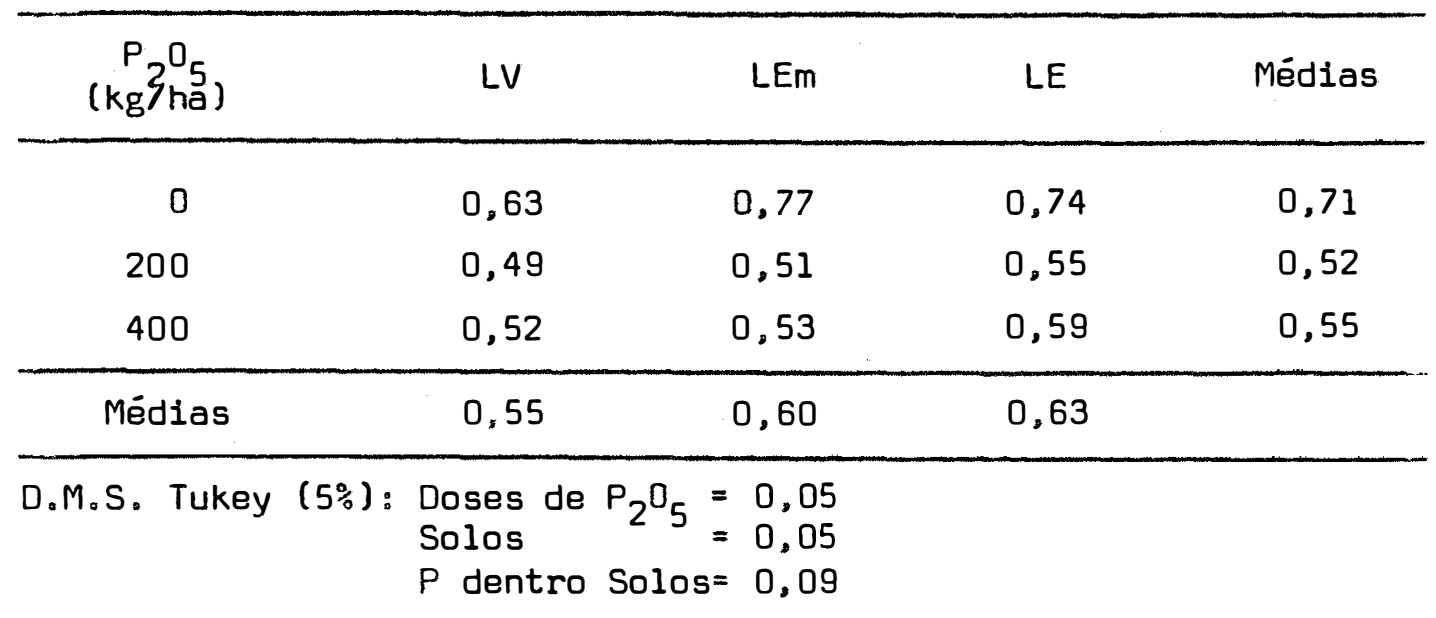

Tabela 28 - Concentrações de Cälcio, em \%, nas Folhas Velhas, em Função das Doses de Fósforo e Solos.

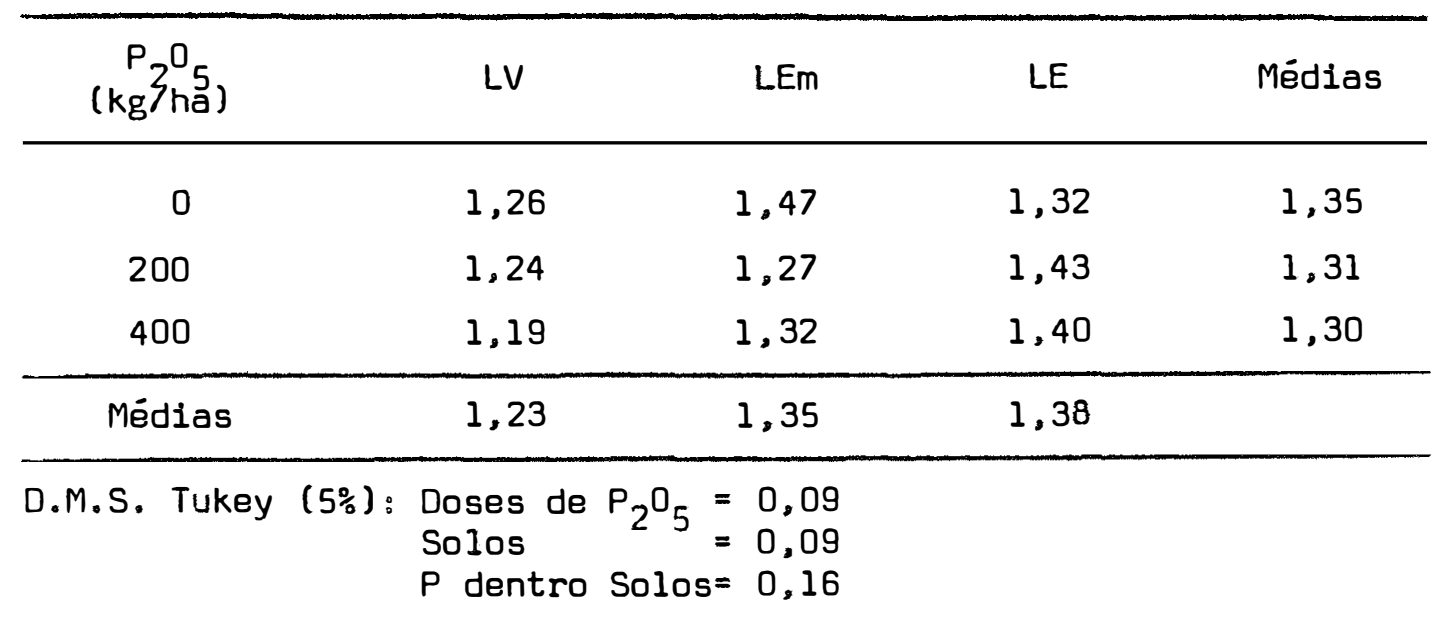


Tabela 29 - Concentrações de Cälcio, em \%, nas Folhas Novas, em Função das Doses de Fósforo e Solos.

\begin{tabular}{ccccc}
\hline $\begin{array}{r}\mathrm{P}^{\mathrm{O}_{5}} \\
(\mathrm{~kg} \text { ha }\end{array}$ & LV & LEm & LE & Médias \\
\hline 0 & 0,90 & 0,93 & 0,96 & 0,93 \\
200 & 0,83 & 0,81 & 0,78 & 0,81 \\
400 & 0,81 & 0,81 & 0,80 & 0,81 \\
\hline Médias & 0,85 & 0,85 & 0,85 & \\
\hline
\end{tabular}

D.M.S. Tukey (5\%): Doses de $\begin{aligned} P_{2} \mathrm{O}_{5} & =0,05 \\ \text { Solos } & =0,05\end{aligned}$

$P$ dentro Solos $=0,08$

Pode-se observar pela Tabela 27, que as variações das concentrações de cálcio nas hastes, em função das doses de fósforo, foram semelhantes nos três solos estudados.As maiores concentrações foram observadas no LEm e LE.O decréscimo observado na concentração desse nutriente, pela adubação fosfatada, deveu-se,provavelmente, a um efeito de diluição, o que pode ser verificado pelo intenso aumen to da matéria seca da parte aérea (Tabela 6). Para as concentrações de cálcio nas folhas velhas, somente foi observado decréscimo entre as doses $\mathrm{O}$ e $200 \mathrm{~kg}$ de $\mathrm{P}_{2} \mathrm{O}_{5} / \mathrm{ha}$, no LEm. Este decréscimo da concentração, pela adubação com fósforo, pode ser atribuído também a um efeito de diluição, devido ao intenso crescimento das plantas suprí das com aquele macronutriente. Os efeitos das doses de fósforo, nas concentrações de cälcio, nas folhas novas, foram semel hantes aos 
nas hastes. Deve-se mencionar, que as variações ocorridas entre as doses 200 e $400 \mathrm{~kg}$ de $\mathrm{P}_{2} \mathrm{O}_{5} / \mathrm{ha}$, não foram significativas.

Poder-se-ia esperar uma elevação das concentrações de cálcio nas diferentes partes da planta pela aplicação das doses de fósforo, visto que, o superfosfato triplo, além de ser fonte de fós foro, fornece também cálcio. O aumento das concentraçōes de cálcio nas folhas de soja foi encontrado por PEREIRA (1972), com o aumento das doses de superfosfato triplo.

Foi observado, também, um aumento das concentrações de cálcio nas folhas novas pela fertilização com zinco. Os dados re lativos a essas concentrações são apresentados na Tabela 30 , observando-se uma elevação no teor do nutriente pelo aumento de 15 para $30 \mathrm{~kg}$ de $\mathrm{ZnSO}_{4} / \mathrm{ha}$, no LV.

Tabela 30 - Concentrações de Cälcio, em \%, nas Folhas Novas, em Fun ção das Doses de Zinco e Solos.

\begin{tabular}{ccccc}
\hline $\begin{array}{c}\text { Sulfato } \\
\text { de Zincs } \\
(\mathrm{kg} / \mathrm{ha})\end{array}$ & LV & LEm & LE & Médias \\
\hline 0 & 0,88 & 0,84 & 0,83 & 0,85 \\
15 & 0,79 & 0,83 & 0,85 & 0,82 \\
30 & 0,87 & 0,88 & 0,88 & 0,88 \\
\hline Médias & 0,85 & 0,85 & 0,85 & \\
\hline D.M.S. Tukey $(5 \%):$ Doses de Sulfato de Zinco & $=0,05$ \\
& $\begin{array}{l}\text { Solos } \\
\text { Zn dentro Solos }\end{array}$ & $=0,05$ & \\
& &
\end{tabular}


46.

\subsection{5 - Concentração de Magnèsio}

As análises da variància, apresentadas de forma resu mida para as diversas partes da planta, acham-se na Tabela 31. Veri fica-se que, para hastes e folhas velhas, houve efeito de solos, fós foro e interação solos x fósforo e para folhas novas, efeito apenas de fósforo.

Tabela 31 - Resumo das Análises da Variāncia das Concentrações de Magnésio na Matéría Seca das Hastes, Folhas Velhas e No vas.

\begin{tabular}{|c|c|c|c|c|}
\hline \multirow{2}{*}{$\begin{array}{l}\text { Causa de } \\
\text { Variação }\end{array}$} & \multirow{2}{*}{ G.L. } & \multicolumn{3}{|c|}{ Q.M. } \\
\hline & & Hastes & Folhas Velhas & Fol has Novas \\
\hline Solos & 2 & $0,014735^{* 2 \%:}$ & $0,032238 \%$ & 0,002679 \\
\hline$P$ & 2 & $0,154807 \%$ & $0,163550 \%$ & $0,115696 \%$ \\
\hline $\mathrm{Zn}$ & 2 & 0,000679 & 0,000816 & 0,000224 \\
\hline Solos $\times P$ & 4 & $0,007768 \%$ & $0,013497 \%$ & 0,002071 \\
\hline Solos $\times \mathrm{Zn}$ & 4 & 0,000540 & 0,004938 & 0,001340 \\
\hline$P \times Z n$ & 4 & 0,000162 & 0,002933 & 0,001257 \\
\hline Solos $\times P \times 2 n$ & 8 & 0,000561 & 0,002930 & 0,000853 \\
\hline Tratamentos & 26 & $0,014570 \%$ & $0,019312 \%$ & $0,010103 * \%$ \\
\hline ResIduo & 27 & 0,001425 & 0,003064 & 0,001266 \\
\hline C.V. & & $11,01 \%$ & $10,02 \%$ & $8,77 \%$ \\
\hline
\end{tabular}

As concentraçöes de magnésio para as diversas partes da planta, em função das doses de fósforo e solos, são encontradas nas Tabelas 32,33 e 34 . 
Tabela 32 - Concentrações de Magnésio, em \%, nas Hastes, em Função das Doses de Fósforo e Solos.

\begin{tabular}{ccccc}
\hline $\begin{array}{c}P_{2} \mathrm{O}_{5} \\
(\mathrm{~kg} \text { há }\end{array}$ & LV & LEm & LE & Médias \\
\hline 0 & 0,38 & 0,52 & 0,45 & 0,45 \\
200 & 0,29 & 0,30 & 0,29 & 0,29 \\
400 & 0,28 & 0,30 & 0,28 & 0,29 \\
\hline Médias & 0,32 & 0,37 & 0,34 & \\
\hline D.M.S. Tukey (5\%): Doses de $\mathrm{P}_{2} \mathrm{O}_{5}$ & $=0,03$ & & \\
& Solos & $=0,03$ & & \\
& P dentro Solos & $=0,05$ &
\end{tabular}

Tabela 33 - Concentrações de Magnésio, em \%, nas Folhas Velhas, em Função das Doses de Fósforo e Solos.

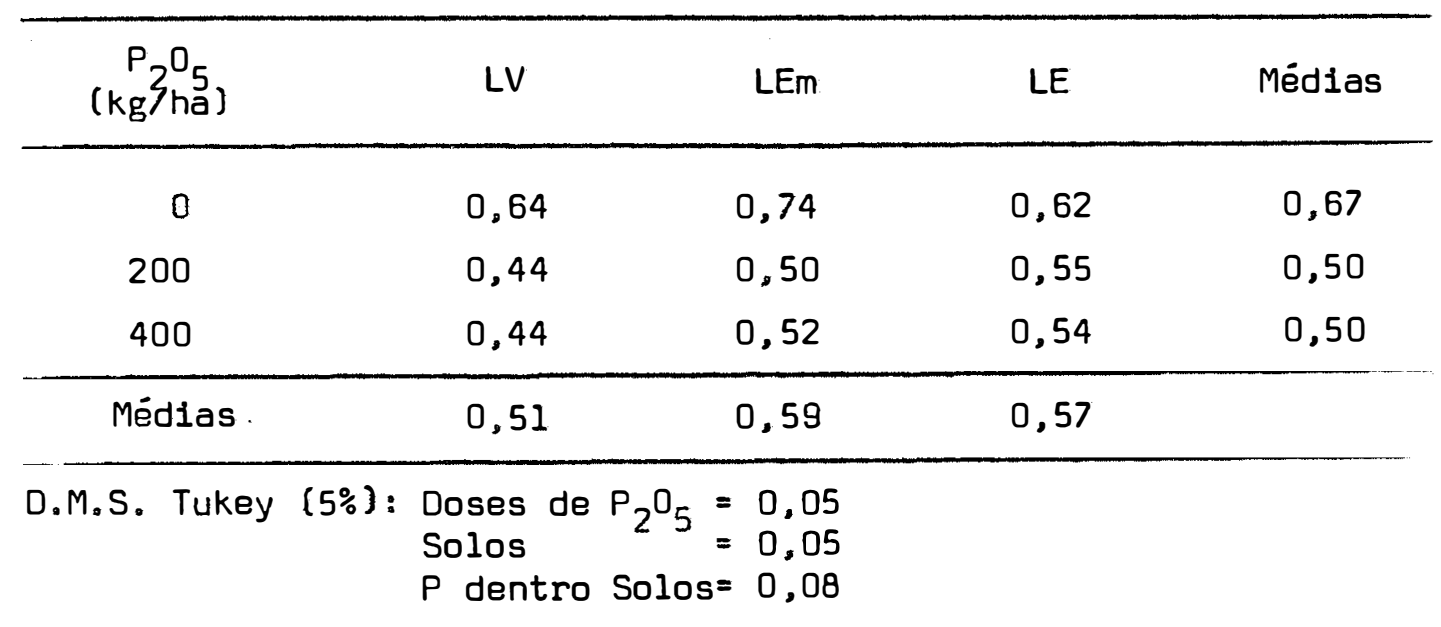


Tabela 34 - Concentrações de Magnésio, em \%, nas Folhas Novas, em Função das Doses de Fósforo e Solos.

\begin{tabular}{ccccc}
\hline $\begin{array}{c}\mathrm{P}_{2} \mathrm{O}_{5} \\
(\mathrm{~kg} / \mathrm{hag})\end{array}$ & LV & LEm & LE & Médias \\
\hline 0 & 0,48 & 0,53 & 0,47 & 0,49 \\
200 & 0,37 & 0,38 & 0,37 & 0,37 \\
400 & 0,34 & 0,35 & 0,36 & 0,35 \\
\hline Médias & 0,40 & 0,42 & 0,40 & \\
\hline D.M.S. Tukey $(5 \%):$ Doses de $\mathrm{P}_{2} \mathrm{O}_{5}=0,03$ & & \\
& Solos & 0,03 & & \\
& P dentro Solos & 0,05 &
\end{tabular}

Para as concentrações de magnésio nas hastes, folhas velhas e novas, Tabelas 32,33 e 34 , respectivamente, verifica-se que ocorreu, dentro dos solos, uma queda da concentração quando se empregou 200 ou $400 \mathrm{~kg}$ de $\mathrm{P}_{2} \mathrm{O}_{5}$ /ha. Entretanto, as diferenças ocorri das entre estas doses não se mostraram significativas. Isto sugere que possa ter havido um efeito de diluição devido ao maior crescimento das plantas supridas em fósforo, visto que, os solos utilizados neste trabalho são conhecidamente pobres neste nutriente.

Apesar do possível efeito de diluição, CONROY e LAMBE (1962) e PEREIRA (1972), trabalhando com tomate e soja, respecti vamente, mostraram reduções das concentrações de magnésio nas folhas, pelo aumento das doses de fósforo aplicadas. 


\subsection{6 - Concentração de Zinco}

Pela Tabela 35 verifica-se que, para hastes e folhas novas, houve efeito de solos, fósforo e zinco. Para folhas velhas, além de ter sido verificado significância de solos, fósforo e zinco, observou-se também o efeito da interação solos $x$ fósforo.

Tabela 35 - Resumo das Anälises da Variāncia das Concentrações de Zinco na Matéría Seca das Hastes, Folhas Velhas e Novas.

\begin{tabular}{|c|c|c|c|c|}
\hline \multirow{2}{*}{$\begin{array}{l}\text { Causa de } \\
\text { Variação }\end{array}$} & \multirow{2}{*}{ G.L. } & \multicolumn{3}{|c|}{ Q.M. } \\
\hline & & Hastes & Folhas Velhas & Fol has Novas \\
\hline Solos & 2 & $306,722198 * 2$ & $6000,574102 * \%$ & $660,073975 \%$ \\
\hline$P$ & 2 & $3337,166659 * *$ & : $5980,574102 \% *$ & $8125,407352^{2 \% \%}$ \\
\hline $\mathrm{Zn}$ & 2 & $142,722198^{*}$ & $5022,574102^{* * *}$ & $1132,573975 \%$ \\
\hline Solos $\times P$ & 4 & 23,305572 & $999,407410 * *$ & 229,601928 \\
\hline Solos $\times \mathrm{Zn}$ & 4 & 29,527793 & 62,490722 & 27,018615 \\
\hline$P \times Z n$ & 4 & 36,472236 & 210,074096 & 93,435241 \\
\hline Solos $\times P \times Z n$ & 8 & 4,111099 & 353,282409 & 48,962921 \\
\hline Tratamentos & 26 & $306,282050 * *$ & $1612,368955^{*}$ & $831,847582 \%$ \\
\hline Residuo & 27 & 27,611111 & 228,629629 & 111,074074 \\
\hline C.V. & & $18,95 \%$ & $20,82 \%$ & $14,97 \%$ \\
\hline
\end{tabular}

Nas Tabelas 36, 37 e 38 encontram-se as concentrações de zinco, para as diversas partes da planta, em função das doses de fósforo e solos. 
Tabela 36 - Concentrações de Zinco, em ppm, nas Hastes, em Função das Doses de Fósforo e Solos.

\begin{tabular}{|c|c|c|c|c|}
\hline${ }_{(k g}{ }^{P_{h}}$ hă $)$ & LV & LEm & LE & Médias \\
\hline 0 & 42,2 & 39,3 & 48,8 & 43,4 \\
\hline 200 & 22,5 & 14,2 & 23,2 & 20,0 \\
\hline 400 & 21,2 & 16,2 & 22,0 & 19,8 \\
\hline Médias & 28,6 & 23,2 & 31,3 & \\
\hline
\end{tabular}

Tabela 37 - Concentrações de Zinco, em ppm, nas Folhas Velhas, em Função das Doses de Fósforo e Solos.

\begin{tabular}{|c|c|c|c|c|}
\hline$\left(k^{2}{ }^{0} h^{5}\right)$ & LV & LEm & LE & Médias \\
\hline 0 & 90,3 & 87,3 & 102,3 & 93,3 \\
\hline 200 & 77,2 & 32,3 & 84,2 & 64,6 \\
\hline 400 & 76,0 & 34,8 & 68,7 & 59,8 \\
\hline Médias & 81,2 & 51,5 & 85,1 & \\
\hline
\end{tabular}


Tabela 38 - Concentrações de Zinco, em ppm, nas Folhas Novas, em Função das Doses de Fósforo e Solos.

\begin{tabular}{|c|c|c|c|c|}
\hline$\left.{ }_{(\mathrm{kg}}{ }^{\mathrm{P}} \mathrm{O}_{5}\right)$ & LV & LEm & LE & Médias \\
\hline 0 & 90,8 & 95,2 & 98,3 & 94,8 \\
\hline 200 & 67,5 & 50,0 & 64,5 & 60,7 \\
\hline 400 & 61,7 & 45,2 & 60,5 & 55,8 \\
\hline Médias & 73,3 & 63,5 & 74,4 & \\
\hline
\end{tabular}

Pela análise das Tabelas 36,37 e 38 , verifica-se que os decréscimos das concentrações de zinco tiveram o mesmo comportamento nos solos estudados, para as diversas partes da planta. Pode-se observar, no entanto, que os decréscimos encontrados no LEm, pe la dose 200 ou $400 \mathrm{~kg}$ de $\mathrm{P}_{2} \mathrm{O}_{5}$ /ha foram mais acentuados que os verificados nos LV e LE. Quando se compara as concentrações de zinco na dose de $200 \mathrm{~kg}$ de $\mathrm{P}_{2} \mathrm{O}_{5} / \mathrm{ha}$, com aquelas na de $400 \mathrm{~kg}$ de $\mathrm{P}_{2} \mathrm{O}_{5} /$ ha, não se verifica diferenças significativas.

Somente se observaram diferenças entre as concentrações na dose de $0 \mathrm{~kg}$ de $\mathrm{P}_{2} \mathrm{O}_{5} /$ ha e aquelas na dose de 200 ou $400 \mathrm{~kg}$ de $\mathrm{P}_{2} \mathrm{O}_{5} /$ ha. Isto sugere novamente um efeito de diluição provocado pe lo crescimento das plantas. Segundo OLSEN (1972), em solos deficien tes em fósforo e tendendo à deficiência ou levemente deficiente em 
zinco disponível, a taxa de crescimento aumenta pela adubação fosfa tada, mas a de absorção de zinco não cresce rapidamente o bastante para manter uma concentração suficiente desse micronutriente na par te aérea. MALAVOLTA e LOPEZ GOROSTIAGA (1974) sugerem que a interação fósforo x zinco podería ser explicada pela operação de váríos processos, dentre eles, o efeito de diluição resultante da mais alta taxa de crescimento causada pelo fosfato.

As concentrações de zinco nas diversas partes da planta, em função das doses de zinco e solos, são apresentadas nas Tabelas 39, 40 e 41 .

Tabela 39 - Concentraçöes de Zinco, em ppm, nas Hastes, em Função das Doses de Zinco e Solos.

\begin{tabular}{ccccc}
\hline $\begin{array}{c}\text { Sulfato } \\
\text { de Zinco } \\
\text { (kg/ha) }\end{array}$ & LV & LEm & LE & Médias \\
\hline 0 & 28,0 & 21,2 & 26,0 & 25,1 \\
15 & 26,5 & 22,8 & 33,0 & 27,4 \\
30 & 31,3 & 25,7 & 35,0 & 30,7 \\
\hline Médias & 28,6 & 23,2 & 31,3 & \\
\hline D.M.S. Tukey (5\%): Doses de Sulfato de Zinco & $=4,3$ & \\
& $\begin{array}{l}\text { Solos } \\
\text { Zn dentro Solos }\end{array}$ & $=7,3$ & \\
& &
\end{tabular}


Tabela 40 - Concentraçöes de Zinco, em ppm, nas Folhas Velhas, em Função das Doses de Zinco e Solos.

\begin{tabular}{ccccc}
\hline $\begin{array}{c}\text { Sulfato } \\
\text { de Zinco } \\
\text { (kg/ha) }\end{array}$ & LV & LEm & LE & Médias \\
\hline 0 & 65,3 & 33,3 & 62,3 & 53,6 \\
15 & 87,3 & 57,0 & 92,8 & 79,0 \\
30 & 90,8 & 64,7 & 100,0 & 85,2 \\
\hline Médias & 81,1 & 51,7 & 85,0 & \\
\hline D.M.S. Tukey (5\%): Doses de Sulfato de Zinco & $=12,5$ \\
& $\begin{array}{l}\text { Solos } \\
\text { Zn dentro Solos }\end{array}$ & 12,5 \\
& & &
\end{tabular}

Tabela 41 - Concentrações de Zinco, em ppm, nas Folhas Novas, em Função das Doses de Zinco e Solos.

\begin{tabular}{ccccc}
\hline $\begin{array}{c}\text { Sulfato } \\
\text { de Zinco } \\
(\mathrm{kg} / \mathrm{ha})\end{array}$ & LV & LEm & LE & Médias \\
\hline 0 & 64,8 & 54,3 & 64,7 & 61,3 \\
15 & 75,3 & 66,7 & 81,0 & 74,3 \\
30 & 79,8 & 69,3 & 77,7 & 75,6 \\
\hline Médias & 73,3 & 63,4 & 74,5 & \\
\hline D.M.S. Tukey (5\%): Doses de Sulfato de Zinco & $=8,7$ \\
& $\begin{array}{l}\text { Solos } \\
\text { Zn dentro Solos }\end{array}$ & 8,7 & \\
& & 15,1
\end{tabular}


Pode-se observar pelas Tabelas 39,40 e 41 , que as concentrações de zinco nas diversas partes da planta, tenderam a au mentar pela adubação com zinco, nos diferentes solos. Entre as doses 15 e $30 \mathrm{~kg}$ de sulfato de zinco/ha não foi observado acréscimo nos teores de zinco. As maiores concentrações foram verificadas no LV e LE. Autores como VIETS et alii (1964), LEE e CRADDOCK (1969), MARTENS et alii (1974) e SALAKO et alii(1975), observaram aumento da concentração de zinco nas folhas de soja, pelo aumento das doses de aplicação desse elemento.

Observa-se que, mesmo na dose $0 \mathrm{~kg}$ de sulfato de zin co/ha, as concentrações de zinco nas folhas velhas e novas apresentavam-se com valores relativamente altos, pois, segundo SMALL JR。 e OHLROGGE (1973), a faixa de suficiēncia desse nutriente para folhas de soja, situa-se entre 21 e 50 ppm. Isto sugere que a soja encontrava-se bem suprida em zinco, e que os aumentos de concentrações ob servados pelas fertilizações com este micronutriente, seriam de luxo. Os níveis satisfatórios das concentrações de zinco nas testemunhas, para o referido micronutriente, poderiam ser devidos à contaminação em zinco pelo superfosfato triplo utilizado como fonte de fósforo, como já mencionado por MASCARENHAS et alii (1977), ou à contaminação pela água destilada utilizada na irrigação. O superfos fato triplo empregado apresentava, segundo sua análise química, um teor de zinco total de 286 ppm. Sabe-se que as doses 200 e 400 kg de $\mathrm{P}_{2} \mathrm{O}_{5}$ /ha equivalem a 444,5 e $889 \mathrm{~kg}$ de superfosfato triplo/ha. Des 
sa forma, a contribuição em zinco pelo adubo fosfatado foi na base de 0,127 e $0,254 \mathrm{~kg}$ de $\mathrm{Zn} / \mathrm{ha}$, o que, por sua vez, equivaleria a 0,552 e $1,104 \mathrm{~kg}$ de $\mathrm{ZnSO}_{4} \cdot 7 \mathrm{H}_{2} \mathrm{O} / \mathrm{ha}$, para as doses 200 e $400 \mathrm{~kg}$ de $\mathrm{P}_{2} \mathrm{O}_{5}$ /ha, respectivamente. Sabe-se também, que a ägua destilada usada na irrigação apresentava um teor de 0,02 ppm de zinco. Com um con sumo médio de 501 de água durante toda a condução do experimento, verifica-se que a contribuição fol na base de $1 \mathrm{mg}$ de zinco/vaso ou $0,37 \mathrm{~kg}$ de $\mathrm{Zn} / \mathrm{ha}$, equivalendo a $1,61 \mathrm{~kg}$ de $\mathrm{ZnSO}_{4} \cdot 7 \mathrm{H}_{2} \mathrm{O} / \mathrm{ha}$. Nos cälcu los, considerou-se uma densidade aparente de 1,3 e uma profundidade de $20 \mathrm{~cm}$ para os solos. 


\section{CONCLUSÕES}

Em função dos resultados obtidos, foi possível chegar às seguintes conclusões:

1 - A produção de matéria seca das plantas e a nodulação aumen taram pela adubação fosfatada.

2 - As plantas cultivadas no solo LEm alcançaram as menores prọ duções de matéria seca.

3 - Os LV e LEm foram os substratos que propiciaram as maiores nodulações da soja.

4 - A fertilização com zinco não provocou aumento na produção de matéria seca das plantas.

5 - As fertilizações com $P$ e $Z n$ provocaram aumentos das concen trações de $P$ e $Z n$, respectivamente, nos tecidos das plantas. 
6 - As concentrações de $\mathrm{N}, \mathrm{Ca}, \mathrm{Mg}$ e $\mathrm{Zn}$ decresceram nas hastes, folhas velhas e novas pela adubação fosfatada, sugerindo um efeito de diluição.

7 - A fertilização com fósforo, na maior dose, provocou translocaçäo do $K$ das folhas velhas para as hastes e folhas novas. 
58.

\section{SUMMAARY}

The purpose of this work was to study the effect of levels of phosphorus and zinc, on the dry matter yield, nodulation and nutrient uptake by soybean (Glycine $\max \left(L_{0}\right)$ Merrill cV. 'UFVI'). The work was conducted under green-house conditions in the Es cola Superior de Agricultura "Luiz de Queiroz". Three levels of P (0, 200 and $\left.400 \mathrm{~kg} \mathrm{P} \mathrm{O}_{5} / \mathrm{ha}\right)$ and three levels of $\mathrm{Zn}(0,15$ and 30 kg of zinc sulfate/ha) were tested in three soils of "Minas Gerais" State. The soils used were a Reddish Yellow Latosol (LV), a Dark Red Latosol medium texture (LEm), and a Dark Red Latosol (LE). The

treatments, a $3^{2} \times 3$ factorial with two replications, were distributed in a completely randomized block design. Each plot, a pot with $7 \mathrm{~kg}$ of soil, received two plants. Before sowing the seeds were inoculated with strains of Rhizobium japonicum. 
The effect of $P$ fertilization was significant on both dry matter yield and nodulation. Zinc fertilization did not bring any increase on the dry matter yield of the plants. The lowest yields were obtained in the LEm. However, in this soil and in the LV, the largest nodulations were observed. The plant $P$ and $Z n$ contents increased with $P$ and $Z n$ fertilizations, respectively. On the other hand, the $\mathrm{N}, \mathrm{Ca}, \mathrm{Mg}$ and $\mathrm{Zn}$ contents decreased with $\mathrm{P}$ fertilization probably due to a dilution effect caused by an intense growth of the plants. The highest level of $P$ fertilization decreased the $K$ concentration in the old leaves and increased in the young leaves and stems indicating that some $K$ translocation occurred. 
60.

\section{LITERATURA CITADA}

XBAHIA, F.G.F.T. de C., 1973. Absorção de zinco em relação à adubação fosfatada e à calagem em dois solos de Minas Gerais. Viçosa, UFV, 38 p. (Tese de Mestrado).

BINGHAM, F.T., 1963. Relation between phosphorus and micronutrients in plants. Soil Sci. Soc. Amer. Proc, Madison, 27: 389 - 391.

BOAWN, L.C.; F.G. VIETS JR. e C.L. CRAWFORD, 1954. Effect of phospha te fertilizers on zinc nutrition of field beans. Soll Science. Bal timore, 78: $1-7$.

BOAWN, L.C. e G.E. LEGGETT, 1964. Phosphorus and zinc concentrations in Russet Burbank Potato tissues in relation to development of zinc deficiency symptons. Soil Sci. Soc. Amer. Proc. Madison, 28: 229232.

BOAWN, L.C. e J.C. BROWN, 1968. Further evidence for a P-Zn imbalance in plants. Soil Sci. Soc. Amer. Proc. Madison, 32: $94-97$. 
BRAGA, J.M.; B.V. OEFELIPO e D. DE ANDRADE, 1972. Adubação da soja em solos sob vegetação de cerrado na região do triàngulo mineiro. Rev. Ceres. Viçosa, 19(201): $52-62$.

BRASIL. Fundação Instituto Brasıle1ro de Geografla e Estatística, 1974. Anuárío Estatístico Brasileiro. 960 p.

BRASIL. Fundação Instituto Brasileiro de Geografia e Estatística, 1976. Anuärío Estatístico Brasile1ro. $816 \mathrm{p}$.

BRITTO,O.P.P. DE SOUSA; A.F. DE CASTRO; W. MENDES; A. JACCOUO; D.P. RAMOS e F.A. COSTA, 1971. Estudo das reações a micronutrientes em latososlo vermelho escuro sob vegetação de cerrado. Pesq. Agropec. Bras. Rio de Jane1ro, 6: $17-22$.

BROWN, A.L.; B.A. KRANTZ e J.L. EDOINGS, 1970. Zinc-phosphorus inte ractions as measured by plant response and soll analysis. Soll Sclence. Baltimore, 110: $415-420$.

BUREAU, F.M.; H.J. MEDERSKI e C.E. EVANS, 1953. The effect of phos phatic fertilizer material and soll phosphorus level on the yield and phosphorus uptake of soybeans. Agronomy Journal. Madison, 45 (4) : $150-154$.

BURLESON, C.A.; A.D. DACUS e C.J. GERARD, 1961. The effect of phosphorus fertili ation on the zinc nutrition of several irrigated crops. Soll Sc1. Soc. Amer. Proc. Madison, 25(5): 365 - 368.

CATANI, R.A. e A.0. JACINTO, 1974. Avaliação da Fertilidade do So10. Mëtodo de Anälise. São Paulo, Livroceres, $61 \mathrm{p}$.

CONROY, E. e J.G.D. LAMBE, 1962. A phosphorus-magnesium interaction in tomato nutrition. Nature. London, 194: 500. 
ELLIS JR., R.; J.F. DAVIS e D.L. THURLOW, 1964. Zinc avallability in calcareous Michigan solls as influenced by phosphorus level and temperature. Soll Sci. Soc. Amer. Proc. Madison, 28: 83 - 86.

EMBRAPA. Empresa Brasileira de Pesquisa Agropecuária. Centro de Pes quisa Agropecuária dos Cerrados. 1976. Relatörio Técnico Anual. $150 \mathrm{p}$.

FLETCHER, H.F. e L.T. KURTZ, 1964. Differential effects of phospho rus fertility on soybean varieties. Soll Scl. Soc. Amer. Proc. Madison, 28: $225-228$.

FREITAS, L.M.M.; A.C. MCCLUNG e N.L. LOTT, 1960. Experimentos de adubação em dols solos de campo cerrado. IBEC Research Institute, Bol. 21, $31 \mathrm{p}$.

GOEPFERT, C.F., 1971. Importáncla do fósforo na nodulação e no ren dimento da soja (Glycine max). Agronomia Sulriograndense. Porto Alegre, 7: $6-9$.

GOEPFERT, C.F. e J.R.J. FREIRE, 1972. Experimento sobre o efeito da calagem e do fösforo em soja (Glycine max (L) Merril). Agronomia Sulriograndense. Porto Alegre, $8(2)$ : 181 - 186.

HOWELL, R.W., 1954. Phosphorus nutrition of soybeans. Plant Physiology. Lancaster, 29(5): $477-483$.

KAMPRATH, E.J. e E.V. MILLER, 1958. Soybean yields as a function of the phosphorus level. Soll Sc1. Soc. Amer. Proc. Madison, 22(4): 317 - 319. 
LANGIN, E.J.; R.C. WARD; R.A. OLSON e H.F. RHOADES, 1962. Factors responsible for poor response of corn and grain sorghum to phosphorus fertilization: II. Lime and $P$ placement effects on P - Zn relations. Soll Sc1.Soc.Amer.Proc.Madison, 26: 574-578.

LEE, C.R. e G.R. CRADDOCK, 1969. Factors affecting plant growth in high-zinc medium: II - Influence of soll treatments on growth of soybeans on strongly acid soll containing zinc from peach sprays. Agronomy Journal. Madison, 61: 565 - 567.

LIMA, L.A. de P.; C. VIEIRA; T. SEDIYAMA e C.S. SEDIYAMA, 1974. Res posta diferencial de quatro variedades de soja à adubação fosfatada e potássica, em tres localidades do Estado de Minas Gerais. Experientiae. Viçosa, 17(4): $63-83$.

LO, S.Y e H.M. REISENAUER, 1968. Zinc nutrition of alfalfa. Agronomy Journal. Madison, 60: $464-466$.

MALAVOLTA, E. e O. LOPEZ GOROSTIAGA, 1974. Studies on the zinc phosphate relationship in plants. Proceeding of the 7 th International Colloquium. Hanover, p. $261-272$.

MARTENS, O.C.; M.T. CARTER e G.0. JONES, 1974. Response of soybeans following six annual aplications of various levels of boron, copper, and zinc. Agronomy Journal. Madison, 66: $82-84$.

MASCARENHAS, H.A.A. e S. MIYASAKA, 1967. Adubaçäo da soja. VI - Efeî tos do enxofre e de värios micronutrientes ( $Z n, C u, B, M n$, Fe e Mol, em solo latosol roxo com vegetação de cerrado. Bragantla.Cam pinas, 26(29): $373-379$. 
MASCARENHAS, H.A.A. e S. MIYASAKA, 1968. Efeito de doses crescentes de calcário, fósforo e potássio em solo latossolo roxo com vegetação de cerrado recém-desbravado. Bragantia. Campinas, 27(25): $279-289$.

MASCARENHAS, H.A.A.; S. MIYASAKA: T. IGUE E E.S. FREIRE, 1970. AdU bação da soja. VIII - Efeito de doses crescentes de calcário,fós foro e potássio em solo podzólico vermelho amarelo, variação Piracicaba. Bragantia. Campinas, 29(8): 81 - 89 .

MASCARENHAS, H.A.A.: R.A.S. KIIHL; V. NAGAI E O.C. BATAGLIA, 1973 , Aplicação de micronutrientes em soja cultivada em solos de cerra do. Agronômico. Campinas, 25: $71-77$.

MASCARENHAS, H.A.A.; S. MIYASAKA; N.R. BRAGA; M.A. C. MIRANDA e 0. TISSELLI FILHO, 1977. Calagem e Adubação da soja. In: A Soja no Brasil Central. Fundação Cargill, p. 85 - 138.

MIYASAKA, S.; J.G. DA SILVA e J.R. GALLD, 1960. Adubação da soja. I - Ensaios preliminares de adubação mineral em terra-roxa-mistü rada. Bragantia. Campinas, 19(42): 667 - 674 .

MIYASAKA, S.: A.C.P. WUTKE e W.R. VENTURINI, 1962. Adubação da soja. II - Adubação mineral em terra-roxa-misturada com argilito do gla cial. Bragantia. Campinas, 21(34): 617 - 630.

MIYASAKA, S.: E.S. FREIRE E H.A.A. MASCARENHAS, 1964 a. Ensaio de adubação da soja e do feijoeiro em solo do arenita Botucatu, com vegetação de cerrado. Bragantia. Campinas, 23(5): 45, 54 .

MIYASAKA, S.; E.S. FREIRE e H.A.A. MASCARENHAS, 1964 b. Adubação da soja. III - Efeito de NPK, do enxofre e de micronutrientes em solo do arenito Botucatu, com vegetação de cerrado. Bragantia. Campinas, $23(7): 65-71$. 
MIYASAKA, S.; C. ALENCAR e E.S. FREIRE, 1966. Resposta da soja à adu bação com N,P, K, S e micronutrientes em solo pobre de Itararé, no sul do planalto paulista. Bragantia. Campinas, 25 (Nota $\left.n^{8} 7\right)$ : XXIX - XXXIII.

MOOY, C.J. E J. PESEK, 1966. Nodulation responses of soybeans to added phosphorus, potassium and calcium salts. Agronomy Journal. Medison, 58: $275-280$.

OLSEN, S.R., 1972. Micronutrient Interactions. In: MORTVEDT, J.J., P.M. GIORDANO e W.L. LINOSAY, Coord. Micronutrients in Agriculture. Madison, Soll Sci. Soc. Amer., p. 243 - 264.

PAULSEN, G.M. e O.A. ROTIMI, 1968. Phosphorus-zinc in two soybean varieties differing in sensitivity to phosphorus nutrition. Soll Sc1. Soc. Amer. Proc. Madison, 32: $73-76$.

PEREIRA, J., 1972. Efeito de fontes e doses de fösforo, na adubação à cultura da soja (Glycine max (L) Merril), em um solo de campo-cerrado. Viçosa, UFV, 70 p. (Tese de Mestrado).

PERKIN - ELMER, 1973. Analytical Methods for Atomic A Absorption. Spectrophotometry. Connecticut, The Perkin - Elmer Corporation.

PIMENTEL GOMES, F., 1976. Curso de Estatfstica Experimental. 6. edi ção, São Paulo, Libraria Nebəl S.A. 430 p.

PIPAEMG. Programa Integrado de Pesquisas Agropecuárias do Estado de Minas Gerais, 1972. Recomendação do Uso de Fertilizantes para 으 Estado de Minas Gerais. 2! Tentativa. Belo Horizonte, Sec. da Agri cultura, $88 \mathrm{p}$. 
PIPAEMG. Programa Integrado de Pesquisas Agropecuárias do Estado de Minas Gerais, 1973. Programa Soja. 42 p. (Boletim Técnico $n^{9} 1$ \}.

SALAKD, E.A.; L.S. MURPHY; P.J. GALLAGHER; S.J. SCHIELD E D.A. HOGAN, 1975. Field and growth chamber investigations of zinc sources for soybeans. Departament of Agronomy, Kansas State University, 61 p. (Report of Progress Grant in Aid).

SARRUGE, J.R. e H.P. HAAG, 1974. Anälises químicas em plantas. Pira clcaba. ESALQ/USP. $55 \mathrm{p}$.

SMALL JR., H.G. e A.J. OHLROGGE, 1973. Plant Analysis as an Aid in Fertilizing Soybeans and Peanuts. In: WALSH, L. M. e J.O. BEATON, Ed. Soll Testing and Plant Analysis.Madison, Soll Sci.Soc. Amer., p. $315-327$.

VIETS JR., F.G.; L.C. BDAWN e C.L. CRAWFORO, 1954. Zinc contents and deficiency symptons of 26 crops grown on a zinc - deficient soll. Soll Science. Baltimore, 78: 305 - 316.

WEBER, J.B. e A.C. CALDWELL, 1962. Soybean chlorosis from heavy ferti lization. Agronomy Journal. Madison, 54(5): $425-427$.

WELCH, C.O.; N.S. HALL e W.L. NELSON, 1949. Utilization of fertilizer and soil phosphorus by soybeans. Soil Sci. Soc. Amer. Proc. Madison, 14: $231-235$. 
67.

APENDICE 
68.

Tabela 1 A - Pesos de Matéria Seca dos Nödulos, Raízes e Parte Aérea, em Fun ção dos Solos, Doses de Fösforo e Zinco. (Média de 2 Repetições)。

\begin{tabular}{|c|c|c|c|c|c|c|c|c|c|c|}
\hline \multirow{2}{*}{$\begin{array}{l}\mathrm{P}_{2} \mathrm{O}_{5} \\
\mathrm{~kg} / \mathrm{ha}\end{array}$} & \multirow{2}{*}{$\begin{array}{l}\text { Sulfato } \\
\text { de } 2 n \text {. } \\
\text { kg/ha }\end{array}$} & \multicolumn{3}{|c|}{ Nódulos (kg/vaso) } & \multicolumn{3}{|c|}{ Raízes (g/vaso) } & \multicolumn{3}{|c|}{ Parte aérea (g/vaso) } \\
\hline & & $L V^{a}=$ & Lem & LE & LV & LEm & LE & LV & LEm & LEE- \\
\hline \multirow[t]{3}{*}{0} & 0 & 5 & 1 & 1 & 1,390 & 1,253 & 1,182 & 2,934 & 2,250 & 2,533 \\
\hline & 15 & 4 & 0 & 1 & 1,509 & 1,113 & 1,236 & 2,934 & 2,179 & 2,478 \\
\hline & 30 & 1 & 1 & 2 & 1,524 & 1,157 & 1,372 & 2,974 & 2,141 & 2,868 \\
\hline \multirow[t]{3}{*}{200} & 0 & 169 & 194 & 202 & 3,538 & 3,230 & 4,000 & 9,938 & 10,614 & 12,504 \\
\hline & 15 & 284 & 159 & 68 & 4,708 & 3,366 & 3,425 & 11,196 & 10,284 & 10,236 \\
\hline & 30 & 296 & 177 & 92 & 4,028 & 3,307 & 3,416 & 11,154 & 9,788 & 11,260 \\
\hline \multirow[t]{3}{*}{400} & 0 & 548 & 443 & 216 & 5,026 & 3,554 & 4,394 & 14,881 & 11,899 & 14,422 \\
\hline & 15 & 465 & 435 & 153 & 4,711 & 3,170 & 4,022 & 14,153 & 12,132 & 12,999 \\
\hline & 30 & 505 & 551 & 220 & 4,262 & 3,614 & 3,629 & 11,584 & 12,501 & 13,174 \\
\hline
\end{tabular}

af Latossolo Vermelho Amarelo.

b/ Latossolo Vermelho Escuro textura média.

c/ Latossolo Vermelho Escuro. 
69.

Tabela 2A - Concentrações de Nitrogênio, em \%, em Função dos Solos, Doses de Fósforo e Zinco e Partes da Planta (Média de 2 Repetições).

\begin{tabular}{|c|c|c|c|c|c|c|c|c|c|c|}
\hline \multirow{3}{*}{$\begin{array}{c}\text { Partes } \\
\text { da } \\
\text { Planta }\end{array}$} & \multirow{3}{*}{$\begin{array}{c}\text { Sulfate } \\
\text { de Zn } \\
\text { kg/ha }\end{array}$} & \multicolumn{3}{|c|}{ LV } & \multicolumn{3}{|c|}{ LEm? } & \multicolumn{3}{|c|}{ LE ${ }^{C^{\prime}}$} \\
\hline & & \multicolumn{3}{|c|}{$\mathrm{P}_{2} \mathrm{O}_{5}(\mathrm{~kg} / \mathrm{ha})$} & \multicolumn{3}{|c|}{$\mathrm{P}_{2} \mathrm{O}_{5}$ (kg/ha) } & \multicolumn{3}{|c|}{$\mathrm{P}_{2} \mathrm{O}_{5} \quad(\mathrm{~kg} / \mathrm{ha})$} \\
\hline & & 0 & 200 & 400 & 0 & 200 & 400 & 0 & 200 & 400 \\
\hline \multirow[t]{3}{*}{ Hastes } & 0 & 3,26 & 0,82 & 0,84 & 2,98 & 0,98 & 0,85 & 3,10 & 0,92 & 1,14 \\
\hline & 15 & 3,16 & 0,95 & 0,76 & 3,10 & 1,12 & 0,80 & 3,01 & 1,44 & 1,15 \\
\hline & 30 & 3,12 & 0,84 & 0,92 & 2,90 & 0,94 & 0,78 & 2,83 & 1,23 & 1,04 \\
\hline \multirow{3}{*}{$\begin{array}{l}\text { Folhas } \\
\text { Velhas }\end{array}$} & 0 & 4,73 & 2,77 & 2,31 & 4,93 & 1,96 & 2,13 & 4,77 & 2,83 & 2,82 \\
\hline & 15 & 4,87 & 2.48 & 2,20 & 4,62 & 2,36 & 2,18 & 4,90 & 3,68 & 3,01 \\
\hline & 30 & 4.78 & 2,35 & 2,16 & 4,68 & 2,36 & 2,45 & 5,24 & 3,33 & 2,84 \\
\hline \multirow{3}{*}{$\begin{array}{l}\text { Folhas } \\
\text { Novas }\end{array}$} & 0 & 4,46 & 3,48 & 2,98 & 4,72 & 2,67 & 2,58 & 4,60 & 3,36 & 3,43 \\
\hline & 15 & 4,31 & 3,42 & 2,82 & 4,46 & 3,44 & 3,05 & 4,79 & 4,18 & 3,42 \\
\hline & 30 & 4,58 & 3,08 & 3,18 & 4,58 & 3,19 & 2,98 & 4,74 & 3,90 & 3,71 \\
\hline
\end{tabular}

af Latossolo Vermelho Amarelo.

b/ Latossolo Vermelho Escuro textura média.

cf Latossolo Vermelho Escuro. 
Tabela $3 A$ - Concentrações de Fósforo, em \%, em Função dos Solos, Doses de Fósforo e Zinco e Partes da Planta. (Média de 2 Repet1çōes).

\begin{tabular}{|c|c|c|c|c|c|c|c|c|c|c|}
\hline \multirow{3}{*}{$\begin{array}{l}\text { Partes } \\
\text { da } \\
\text { Planta }\end{array}$} & \multirow{3}{*}{$\begin{array}{l}\text { Sulfat } \\
\text { de } \mathrm{Zn} \\
\mathrm{kg} / \mathrm{ha}\end{array}$} & \multicolumn{3}{|c|}{$L V=$} & \multicolumn{3}{|c|}{ LEm } & \multicolumn{3}{|c|}{$L E-$ - } \\
\hline & & \multicolumn{3}{|c|}{$\mathrm{P}_{2} \mathrm{O}_{5}(\mathrm{~kg} / \mathrm{ha})$} & \multicolumn{3}{|c|}{$\mathrm{P}_{2} \mathrm{O}_{5}(\mathrm{~kg} / \mathrm{ha})$} & \multicolumn{3}{|c|}{$\mathrm{P}_{2} \mathrm{O}_{5}(\mathrm{~kg} / \mathrm{ha})$} \\
\hline & & 0 & 200 & 400 & 0 & 200 & 400 & 0 & 200 & 400 \\
\hline \multirow[t]{3}{*}{ Hastes } & 0 & 0,048 & 0,072 & 0,056 & 0,046 & 0,048 & 0,048 & 0,045 & 0,068 & 0.062 \\
\hline & 15 & 0,042 & 0,064 & 0,064 & 0,041 & 0,046 & 0,051 & 0,046 & 0,076 & 0,056 \\
\hline & 30 & 0,048 & 0,059 & 0,062 & 0,044 & 0,042 & 0,056 & 0,061 & 0,066 & 0,074 \\
\hline \multirow{3}{*}{$\begin{array}{l}\text { Folhas } \\
\text { Velhas }\end{array}$} & 0 & 0,085 & 0,098 & 0.101 & 0,076 & 0,051 & 0,086 & 0,080 & 0,102 & 0,101 \\
\hline & 15 & 0,066 & 0,099 & 0,094 & 0,058 & 0,077 & 0,088 & 0,064 & 0,118 & 0,107 \\
\hline & 30 & 0,064 & 0,094 & 0,102 & 0,054 & 0,084 & 0,102 & 0,058 & 0,122 & 0,139 \\
\hline \multirow{3}{*}{$\begin{array}{l}\text { Folhas } \\
\text { Novas }\end{array}$} & 0 & 0,133 & 0,179 & 0,176 & 0,157 & 0,122 & 0,156 & 0,140 & 0,186 & 0,172 \\
\hline & 15 & 0,138 & 0,174 & 0,195 & 0,134 & 0,125 & 0,189 & 0,138 & 0,188 & 0,186 \\
\hline & 30 & 0,148 & 0,160 & 0,184 & 0,132 & 0,126 & 0,196 & 0,140 & 0,181 & 0,214 \\
\hline
\end{tabular}

af Latossolo Vermelho Amarelo.

b/ Latossolo Vermelho Escuro textura médla.

c/ Latossolo Vermelho Escuro. 
Tabela 4A - Concentrações de Potássio, em \%, em Função dos Salos, Doses de Fósforo e Zinco e Partes da Planta. (Média de 2 Repetições).

\begin{tabular}{|c|c|c|c|c|c|c|c|c|c|c|}
\hline \multirow{3}{*}{$\begin{array}{l}\text { Partes } \\
\text { da } \\
\text { Planta }\end{array}$} & \multirow{3}{*}{$\begin{array}{l}\text { Sulfato } \\
\text { de } \mathrm{Zn} \\
\mathrm{kg} / \mathrm{ha}\end{array}$} & \multicolumn{3}{|c|}{$L V=$} & \multicolumn{3}{|c|}{$\mathrm{LEm}^{\mathrm{B}}$} & \multicolumn{3}{|c|}{$L E-C$} \\
\hline & & \multicolumn{3}{|c|}{$\mathrm{P}_{2} \mathrm{O}_{5}(\mathrm{~kg} / \mathrm{ha})$} & \multicolumn{3}{|c|}{$\mathrm{P}_{2} \mathrm{O}_{5}$ (kg/ha) } & \multicolumn{3}{|c|}{$\mathrm{P}_{2} \mathrm{O}_{5}$ (kg/ha) } \\
\hline & & 0 & 200 & 400 & 0 & 200 & 400 & 0 & 200 & 400 \\
\hline \multirow[t]{3}{*}{ Hastes } & 0 & 0,71 & 1,42 & 0,88 & 0,76 & 0,70 & 0,81 & 0,84 & 1,08 & 1,08 \\
\hline & 15 & 0,66 & 1,16 & 1,00 & 0,76 & 0,84 & 0,85 & 0,78 & 1,39 & 1,08 \\
\hline & 30 & 0,77 & 1,12 & 1,20 & 0,78 & 0,88 & 0,84 & 0,86 & 1,42 & 1,24 \\
\hline \multirow{3}{*}{$\begin{array}{l}\text { Folhas } \\
\text { Velhas }\end{array}$} & 0 & 1,20 & 1,39 & 1,12 & 1,12 & 0,81 & 0,62 & 1,28 & 1,24 & 1,00 \\
\hline & 15 & 1,31 & 1,20 & 1,16 & 1,08 & 0,81 & 0,80 & 1,31 & 1,31 & 1,00 \\
\hline & 30 & 1,08 & 1,27 & 1,24 & 1,12 & 0,92 & 0,84 & 1,12 & 1,42 & 1,28 \\
\hline \multirow[t]{3}{*}{ Folhas } & 0 & 1,54 & 1,88 & 1,66 & 1,76 & 1,54 & 1,54 & 1,72 & 1,80 & 1,70 \\
\hline & 15 & 1,58 & 1.77 & 1,81 & 1,50 & 1,70 & 1,81 & 1,54 & 1,85 & 1,69 \\
\hline & 30 & 1,58 & 1,77 & 1,81 & 1,46 & 1,54 & 1,77 & 1,55 & 1,92 & 1.77 \\
\hline
\end{tabular}

a/ Latossolo Vermelho Amarelo.

b/ Latossolo Vermelho Escuro textura média.

c/ Latossolo Vermelho Escuro. 
Tabela 5A - Concentrações de Cálcio, em \%, em Função dos Solos, Doses de Fósforo e Zinco e Partes da Planta. (Médias de 2 Repetições).

\begin{tabular}{|c|c|c|c|c|c|c|c|c|c|c|}
\hline \multirow{3}{*}{$\begin{array}{c}\text { Partes } \\
\text { da } \\
\text { Planta }\end{array}$} & \multirow{3}{*}{$\begin{array}{l}\text { Sulfato } \\
\text { de } \mathrm{Zn} \\
\mathrm{kg} / \mathrm{ha}\end{array}$} & \multicolumn{3}{|c|}{$L V^{a}=$} & \multicolumn{3}{|c|}{ LEm ${ }^{\mathrm{b} /}$} & \multicolumn{3}{|c|}{ LE- $=$} \\
\hline & & \multicolumn{3}{|c|}{$\mathrm{P}_{2} \mathrm{O}_{5}$ (kg/ha) } & \multicolumn{3}{|c|}{$\mathrm{P}_{2} \mathrm{O}_{5}$ (kg/ha) } & \multicolumn{3}{|c|}{$\mathrm{P}_{2} \mathrm{O}_{5}$ (kg/ha) } \\
\hline & & 0 & 200 & 400 & 0 & 200 & 400 & 0 & 200 & 400 \\
\hline \multirow[t]{3}{*}{ Hastes } & 0 & 0,66 & 0,52 & 0,53 & 0,78 & 0,50 & 0,54 & 0,72 & 0,56 & 0,60 \\
\hline & 15 & 0,56 & 0,48 & 0,48 & 0,76 & 0,50 & 0,52 & 0,72 & 0,56 & 0,60 \\
\hline & 30 & 0,68 & 0,48 & 0,56 & 0,78 & 0,53 & 0,53 & 0,76 & 0,53 & 0,56 \\
\hline \multirow{3}{*}{$\begin{array}{l}\text { Folhas } \\
\text { Velhas }\end{array}$} & 0 & 1,38 & 1,34 & 1,13 & 1,44 & 1,20 & 1,39 & 1,34 & 1,42 & 1,24 \\
\hline & 15 & 1,24 & 1.19 & 1,10 & 1,49 & 1,16 & 1,25 & 1,34 & 1,54 & 1,44 \\
\hline & 30 & 1,14 & 1,18 & 1,35 & 1,48 & 1,44 & 1.34 & 1,29 & 1,34 & 1,54 \\
\hline \multirow{3}{*}{$\begin{array}{l}\text { Folhas } \\
\text { Novas }\end{array}$} & 0 & 0,94 & 0,90 & 0,79 & 0,96 & 0,74 & 0,82 & 0,91 & 0,82 & 0,75 \\
\hline & 15 & 0,83 & 0,80 & 0,74 & 0,89 & 0,82 & 0,78 & 0,97 & 0,74 & 0,84 \\
\hline & 30 & 0,92 & 0,80 & 0,90 & 0,94 & 0,86 & 0,84 & 1,00 & 0,79 & 0,83 \\
\hline
\end{tabular}

a/ Latossolo Vermelho Amarelo.

b/ Latossolo Vermelho Escuro textura média.

c/ Latossolo Vermelho Escuro. 
Tabela 6A - Concentrações de Magnésio, em \%, em Função dos Solos, Doses de Fósforo e Zinco e Partes da Planta. (Médias de 2 Repetições).

\begin{tabular}{|c|c|c|c|c|c|c|c|c|c|c|}
\hline \multirow{3}{*}{$\begin{array}{c}\text { Partes } \\
\text { da } \\
\text { Planta }\end{array}$} & \multirow{3}{*}{$\begin{array}{l}\text { Sulfato- } \\
\text { de Zn } \\
\mathrm{kg} / \mathrm{ha}\end{array}$} & \multicolumn{3}{|c|}{$L V^{a /}$} & \multicolumn{3}{|c|}{ LEm } & \multicolumn{3}{|c|}{ LEE } \\
\hline & & \multicolumn{3}{|c|}{$\mathrm{P}_{2} \mathrm{O}_{5}(\mathrm{~kg} / \mathrm{ha})$} & \multicolumn{3}{|c|}{$\mathrm{P}_{2} \mathrm{O}_{5} \quad(\mathrm{~kg} / \mathrm{ha})$} & \multicolumn{3}{|c|}{$\mathrm{P}_{2} \mathrm{O}_{5}(\mathrm{~kg} / \mathrm{ha})$} \\
\hline & & 0 & 200 & 400 & 0 & 200 & 400 & 0 & 200 & 400 \\
\hline \multirow[t]{3}{*}{ Hastes } & 0 & 0,40 & 0,31 & 0,27 & 0,51 & 0,30 & 0,30 & 0,46 & 0,29 & 0,30 \\
\hline & 15 & 0,36 & 0,28 & 0,27 & 0,53 & 0,30 & 0,29 & 0,46 & 0,30 & 0,28 \\
\hline & 30 & 0,38 & 0,26 & 0,29 & 0,52 & 0,28 & 0,30 & 0,44 & 0,29 & 0,26 \\
\hline \multirow{3}{*}{$\begin{array}{l}\text { Folhas } \\
\text { Velhas }\end{array}$} & 0 & 0,68 & 0,50 & 0,41 & 0,70 & 0,47 & 0,54 & 0,62 & 0.50 & 0,49 \\
\hline & 15 & 0,64 & 0,42 & 0,43 & 0,76 & 0,47 & 0,49 & 0,64 & 0,58 & 0,56 \\
\hline & 30 & 0,59 & 0,40 & 0,48 & 0,74 & 0,55 & 0,54 & 0,60 & 0,56 & 0,58 \\
\hline \multirow{3}{*}{$\begin{array}{l}\text { Folhas } \\
\text { Novas }\end{array}$} & 0 & 0,53 & 0,38 & 0,32 & 0,54 & 0,34 & 0,34 & 0,47 & 0,36 & 0,34 \\
\hline & 15 & 0,46 & 0,36 & 0,34 & 0,56 & 0,40 & 0,34 & 0,49 & 0,36 & 0,38 \\
\hline & 30 & 0,47 & 0,36 & 0,36 & 0,51 & 0,38 & 0,36 & 0,46 & 0,38 & 0,36 \\
\hline
\end{tabular}

a/ Latossolo Vermelho Amarelo.

b/ Latossolo Vermelho Escuro textura média.

c/ Latossolo Vermelho Escuro. 
74.

Tabela 7A - Concentraçōes de Zinco, em ppm, em Função dos Solos, Doses de Fósforo e Zinco e Partes da Planta. (Média de 2 Repetições).

\begin{tabular}{|c|c|c|c|c|c|c|c|c|c|c|}
\hline \multirow{3}{*}{$\begin{array}{c}\text { Partes } \\
\text { da } \\
\text { Planta }\end{array}$} & \multirow{3}{*}{$\begin{array}{l}\text { Sulfato } \\
\text { de } \mathrm{Zn} \\
\mathrm{kg} / \mathrm{ha}\end{array}$} & \multicolumn{3}{|c|}{$L V^{a}=$} & \multicolumn{3}{|c|}{ LEm } & \multicolumn{3}{|c|}{ LE $=$} \\
\hline & & \multicolumn{3}{|c|}{$\mathrm{P}_{2} \mathrm{O}_{5}$ (kg/ha) } & \multicolumn{3}{|c|}{$\mathrm{P}_{2} \mathrm{O}_{5}(\mathrm{~kg} / \mathrm{ha})$} & \multicolumn{3}{|c|}{$\mathrm{P}_{2} \mathrm{O}_{5}$ (kg/ha) } \\
\hline & & 0 & 200 & 400 & 0 & 200 & 400 & 0 & 200 & 400 \\
\hline \multirow[t]{3}{*}{ Hastes } & 0 & 40 & 21 & 23 & 34 & 13 & 16 & 42 & 17 & 18 \\
\hline & 15 & 38 & 22 & 20 & 39 & 15 & 14 & 49 & 27 & 23 \\
\hline & 30 & 48 & 25 & 20 & 44 & 14 & 18 & 55 & 26 & 24 \\
\hline \multirow{3}{*}{$\begin{array}{l}\text { Folhas } \\
\text { Velhas }\end{array}$} & 0 & 57 & 78 & 62 & 56 & 19 & 25 & 88 & 53 & 46 \\
\hline & 15 & 110 & 69 & 84 & 104 & 30 & 38 & 102 & 102 & 74 \\
\hline & 30 & 104 & 85 & 83 & 104 & 48 & 42 & 117 & 97 & 86 \\
\hline \multirow{3}{*}{$\begin{array}{l}\text { Folhas } \\
\text { Novas }\end{array}$} & 0 & 86 & 54 & 54 & 85 & 37 & 41 & 92 & 50 & 52 \\
\hline & 15 & 84 & 75 & 67 & 95 & 57 & 48 & 106 & 72 & 64 \\
\hline & 30 & 102 & 74 & 64 & 106 & 56 & 46 & 97 & 70 & 66 \\
\hline
\end{tabular}

